\title{
Spread-F characteristics at the southern anomaly crest in South America during the descending phase of solar cycle 24
}

Gilda de Lourdes González ( $\square$ gilda.gonzalez@unsta.edu.ar)

Universidad Nacional de Tucumán https://orcid.org/0000-0003-4989-3527

\section{Research Article}

Keywords: Low latitude lonosphere, Equatorial Spread-F, Plasma Bubbles, lonospheric Irregularities

Posted Date: April 22nd, 2021

DOl: https://doi.org/10.21203/rs.3.rs-452354/v1

License: (c) (i) This work is licensed under a Creative Commons Attribution 4.0 International License.

Read Full License 


\section{Abstract}

Ionospheric F-region irregularities can acutely affect navigation and communication systems. To develop predictive capabilities on their occurrence, it is key to understand their variabilities in a wide range of time scales. Previous studies at low latitudes in South America have been performed mostly for the eastern sector, and fewer efforts have been done in the Argentinian region. This work presents the analysis of the spread- $\mathrm{F}$ (range spread- $\mathrm{F}$, frequency spread- $\mathrm{F}$ and strong spread- $\mathrm{F}$ ) and plasma bubble occurrence characteristics near the southern crest of the Equatorial Ionization Anomaly (Tucumán, $26.8^{\circ} \mathrm{S}, 65.2^{\circ} \mathrm{W}$; magnetic latitude $15.5^{\circ} \mathrm{S}$ ). We used ionosonde and Global Positioning System (GPS) data from November 2014 to December 2019 for different solar and geomagnetic conditions. The data shows that spread- $F$ and plasma bubble occurrence rates peak in summer and are minimum in equinox and winter, respectively. There is, usually, a negative correlation between each type of spread-F and solar activity, whereas the opposite happens for plasma bubbles. Geomagnetic activity suppresses the generation of spread-F in equinox and summer and enhances it in winter. Plasma bubble occurrence is higher during disturbed days than during quiet days, but under medium solar activity, summer months register more plasma bubbles in quiet conditions. Range spread-F observed in winter under low solar activity is not associated with plasma bubbles originated at the magnetic equator. These results contribute to the knowledge necessary to improve the prediction of the spatial and temporal distribution of the night-time ionospheric irregularities.

\section{Introduction}

lonospheric irregularities are regions in the ionosphere with electron density noticeably different from the background, caused by plasma instability processes. Their scale sizes range from centimetres to hundreds of kilometres, and the duration can vary between minutes and several hours. It has been an important subject of investigation since it was discovered (Booker \& Wells 1938), mainly due to its adverse effects on communication and navigation systems. To mitigate this negative influence is necessary to improve the understanding of this ionospheric phenomenon and improve our prediction capabilities. The plasma density irregularities depend on local time, season, latitude and longitude, and solar and geomagnetic activities besides their day-to-day variability (Abduet al. 1985; Pietrella et al. 2017; Tsunoda 1985; Yizengaw \& Groves 2018). The analysis of their characteristics in different locations and periods is essential.

At equatorial and low latitude regions, the generation of ionospheric irregularities can be attributed to the gravitational Rayleigh-Taylor instability mechanism (Kelley 2009). Their initiation is related to the vertical transport of plasma associated with zonal electric fields. These electric fields could be generated by the ionospheric dynamo or imposed from the magnetosphere. Irregularities are most severe at night; a condition for their generation is that the $\mathrm{E}$ layer conductivity can not short out the driving electric field.

Several researchers have studied the occurrence of $\mathrm{F}$ region irregularities in the equatorial ionization anomaly (EIA) crest region in different longitudinal sectors, using data from a wide variety of diagnostic 
techniques: ionosonde, ground-based Global Navigation Satellite System (GNSS), optical imaging techniques, radar observations and in situ satellite measurements (Cueva et al. 2013; Li et al. 2020; Muella et al. 2010; Pietrella et al. 2017; Reinisch et al. 2004; Sahai et al. 1994; Timoçin et al. 2020). They found that multiple factors control the occurrence of irregularities such as the pre-reversal enhancement (PRE), seed perturbations, density gradient at the $\mathrm{F}$ layer bottom side and the trans-equatorial winds (Abdu et al. 2020; Fejer et al. 1999; Yokoyama et al. 2004).

If irregularities are present in the $F$ region above an ionosonde, a backscatter signature called spread- $F$ is seen in ionograms. The effect of broadening in frequency is known as frequency spread-F (FSF) and in height, range spread-F (RSF) (Piggott \& Rawer 1978). When the RSF extends beyond the local critical frequency of the F2 layer (foF2), it is denominated strong range spread-F (SSF) (Shi et al. 2011). At low latitudes, RSF is often associated with plasma bubbles. These are large-scale depletions of $F$ region electron density started at the bottom side and extended up to the top side of the layer. FSF is related to smaller-scale decaying irregularities near the $\mathrm{F}$ region peak (Abdu et al. 1998).

A total electron content (TEC) depletion is a sudden reduction of TEC followed by a recovery to a level near the value preceding the depletion (Valladares et al. 2004). Many researchers have pointed out that these are a manifestation of plasma bubbles (DasGupta A. et al. 1983; Tsunoda \& Towle 1979; Weber et al. 1996; Shetti et al. 2019). Global Positioning System (GPS) signal delays are proportional to the TEC along the satellite-receiver line of sight. Thus, GPS data can derive the TEC (Çepni et al. 2013; Dashora \& Pandey 2005).

The seasonal/longitudinal distribution of the irregularities occurrence rate depends on the magnetic declination angle, i.e., in the geometry between the geomagnetic field line and the terminator line (Tsunoda 1985). In the Brazilian region, earlier works showed a high plasma bubble occurrence rate during the December solstice and a low occurrence during the June solstice (Abdu et al. 1998; Sahai et al. 1994). Chum et al. (2016) examined the spread-F behaviour over Tucumán and Taiwan in 2014 based on measurements by continuous Doppler sounding. They observed the highest occurrence rate from September to March in Tucumán, and around equinoxes in Taiwan. Alfonsi et al. (2013) performed spread-F statistics of occurrence at Tucumán during October 2010-September 2011. They reported that the occurrence of all types of spread- $F$ was maximum in summer and minimum in winter.

The effects of solar and geomagnetic activities on spread-F vary with latitude and longitude. Previous studies investigated the relationship between the spread-F occurrence and the geomagnetic and solar conditions at low latitudes using geophysical indices (Kp, Dst, F10.7 and Sn) (Aquino \& Sreeja 2013; Bowman \& Mortimer 2003; Kotulak et al. 2020). Whalen (2003) suggested that plasma bubble occurrence decrease with the Kp index during equinox and December solstice in South America. Becker-Guedes et al. (2004) discussed the spread-F occurrence during geomagnetic storms at three stations in the eastward Brazilian sector. They concluded that during the low equatorial plasma bubble occurrence season and transition season, the geomagnetic activity helped in the generation of plasma bubbles and inhibited it during the high plasma bubble occurrence season. Abdu et al. (1998) examined data from three stations 
in South America, including Tucumán, for four intervals: 1980-81 (F10.7=161.5) and 1988-89

(F10.7=173.8) representing solar maximum conditions, and 1984-85/1986-87 (F10.7=83.7/73.6)

representing solar minimum conditions. Their results showed that there was an increase in the spread-F occurrence rate with solar flux. Also, the spread-F occurrence was maximum in the summer months at Tucumán.

Although many researchers have discussed the characteristics of ionospheric irregularities at low latitudes, some aspects still need to be further investigated to better understand the spatial and temporal variability of spread-F and plasma bubbles. Therefore, the analysis of large data sets for various solar and magnetic conditions is useful. In South America, most studies have been done for the eastern Brazilian region, characterized by a magnetic declination angle of $\sim 20^{\circ} \mathrm{W}$. Whereas the magnetic declination angle in Tucumán is $\sim 7^{\circ} \mathrm{W}$. Albeit some works have examined the spread-F occurrence in Tucumán (Abdu et al. 1998; Alfonsi et al. 2013; Cabrera et al. 2010; Pezzopane et al. 2013), we considered herein a longer period of analysis: November 2014 to December 2019. This work aims to contribute to the knowledge of the characteristics of spread-F and plasma bubbles during different local times, seasons, solar and geomagnetic conditions at the southern crest of the EIA. To that end, we analysed the occurrence percentages of RSF, FSF, SSF, and TEC depletion using ionosonde and GPS data sets at Tucumán during the descending phase of solar cycle 24.

\section{Methodology}

We studied the irregularities occurrence at Tucumán, Argentina $\left(26.8^{\circ} \mathrm{S}, 65.2^{\circ} \mathrm{W}\right.$; magnetic latitude $15.5^{\circ} \mathrm{S}$ ), a station near the southern crest of the equatorial ionization anomaly (EIA) (Figure 1). We analysed 1038 days of ionosonde data and 1310 days of GPS data. The period considered was November 2014 to December 2019, the descending phase of Solar Cycle 24, as it is indicated by the sunspot number Sn (http://www.sidc.be/silso/dayssnplot). During 2019 the monthly mean sunspot number was between 0.4 to 9.9 and the yearly mean sunspot number was 3.6. From November 2014 to December 2015, the monthly mean Sn was between 54.5 and 112.9. The yearly mean Sn for 2015 was 69.8 and the average Sn for Nov-Dec 2014 was 113.6.

We manually examined the ionograms recorded by the Vertical Incidence Pulsed lonospheric Radar (VIPIR) by following the Manual of lonogram Scaling (Wakaiet al. 1987) and the U.R.S.I Handbook (Piggott \& Rawer 1978). The VIPIR operates between 0.3 and $25 \mathrm{MHz}$ with a sounding repetition rate of 5 minutes (Bullett 2008). The data availability is shown in figure 2 and the ionograms can be downloaded from the website of the Low Latitude lonospheric Sensor Network (LISN) (http://lisn.igp.gob.pe). We analysed the occurrence rate (equation 1) of three types of spread-F: RSF, FSF, and SSF (Figure 3 ) during 18:00-06:00 LT (UT=LT+4) and their mean duration (equation 2).

\section{See equations 1 and 2 in the supplementary files.}

To examine the seasonal behaviour, we grouped the data into March equinox (March and April), June solstice (May, June, July, and August), September equinox (September and October), and December 
solstice (November, December, January, and February). We considered F10.7 and Ap index to identify the solar and geomagnetic conditions. F10.7 $\leq 100,100<\mathrm{F} 10.7<180$, and F10.7 $\geq 180$ represent low, medium, and high solar activity, respectively (Abdu et al. 2003). Ap $<12$ indicates geomagnetic quiet days and $A p \geq 12$ disturbed days. F10.7 is provided by Dominion Radio Astrophysical Observatory and Natural Resources Canada (https://www.spaceweather.gc.ca/solarflux/sx-en.php) and Ap index is produced by Geomagnetic Observatory Niemegk, GFZ German Research Centre for Geosciences (https://www.gfzpotsdam.de/en/home/).

To compare the behaviour of RSF and plasma bubbles, we considered TEC depletions greater than 5 TECu $\left(1 \mathrm{TECu}=10^{16}\right.$ electron $/ \mathrm{m}^{2}$ ) to be associated with plasma bubbles (Magdaleno et al. 2012). Hence, we used ground-based GPS-TEC data at Tucumán to calculate the plasma bubbles occurrence rate (number of days with TEC depletions greater than 5 TECu, divided by the total number of days analysed).

The Receiver INdependent EXchange (RINEX) files are available at the LISN website, unfortunately, there are no measurements for September-December 2017 and April-December 2019. The vertical TEC (VTEC) was calculated from GPS observables got from RINEX files using the analysis code developed by Seemala \& Valladares (2011). The effects of multi-path were reduced by applying a $30^{\circ}$ elevation mask. We derived TEC every 10 seconds.

\section{Results}

\subsection{Monthly and seasonal variations of the spread-F occurrence}

During the period analysed, the most common type of spread-F was RSF $(64.9 \%)$ and the least frequent was SSF (3.6\%). According to the monthly occurrence rate (Figure 4-8), RSF began at 20-22 LT and lasted until 5-6 LT. The peak occurrence rate was usually around 23-1 LT, whereas for May-August the maximum came up later. FSF generally arose after midnight and peaked around 3 LT. The SSF occurrence rate was higher during November, December 2014, and February and November 2015, and almost zero during other months. It developed from $\sim 20$ LT to $\sim 1$ LT with a peak at $\sim 23$ LT.

September equinox registered the lowest spread-F occurrence (61\%) and December solstice the highest (84\%). Figure 9 depicts the seasonal spread-F occurrence rate for each year. December solstice presented the highest occurrence every year (from 62\% in 2015 to 95\% in 2017) except in 2018 when the maximum was in June solstice (90\%). The season with the lowest occurrence percentage (12\%) was June solstice, 2015. It is worth mentioning that 2018 showed a high occurrence of spread-F in all seasons, between $70 \%$ in September equinox and $90 \%$ in June solstice.

RSF occurrence rate was highest in November 2017-February 2018 (91.2\%), FSF in November 2016February 2017 (81.7\%), and both showed their lowest occurrence in July-August 2015 (11.5\% for RSF and $7.7 \%$ for FSF). SSF occurrence was sparse and the highest value was in November 2014-February 2015 (34.5\%). RSF was more frequent than the other types of spread-F in all seasons except between September 2016 and April 2017 when FSF occurrence was higher (Figure 10). 
The mean RSF duration tended to increase during the period studied, whereas the opposite happened for the FSF and SSF (Figure 11). RSF lasted around 1-3 hours, FSF 0.5-2 hours, and SSF 1.4-2.7 hours. We did not observe any clear seasonal trend.

\subsection{Spread-F occurrence rate during different solar and geomagnetic conditions}

Spread-F occurrence increased between 2016 (53.3\%) when the mean F10.7 was 88.7 sfu (sfu is solar flux unit: $10^{-22} \mathrm{Wm}^{-2} \mathrm{~Hz}^{-1}$ ) and 2018 (84.5\%) when the mean F10.7 was $69.9 \mathrm{sfu}$, and decreased in 2019 (78.2\%) when the mean F10.7 was 77.3 sfu. Regarding the different types of spread-F, RSF and FSF occurrence rate generally increased when the F10.7 index decreased, especially between 2015 and 2018 . This inverse correlation between spread-F and solar flux was not observed for SSF (Figure 12). Similarly, RSF and FSF increased when the mean Ap index decreased between 2015 and 2019.

For the period examined here, there were few days with high solar activity (F10.7 $\geq 180)$, and just one had ionosonde data available $(4 / 9 / 17, \mathrm{~F} 10.7=186)$. So, in this analysis, we only considered days with low $(\mathrm{F} 10.7 \leq 100)$ and medium $(100<\mathrm{F} 10.7<180)$ solar activity levels. The RSF occurrence rate showed the largest values under low solar activity for all seasons except in September equinox when RSF occurrence rate was $6.8 \%$ higher during medium solar activity than during low activity (Figure 13). RSF was not present for March equinox during medium solar activity. FSF occurrence was maximum during low solar activity for all seasons, and it was not observed in the June solstice during medium solar activity. SSF was only seen during low solar activity except in the December solstice when its occurrence rate was higher during medium solar activity $(22.1 \%)$ than during low solar activity $(11.4 \%)$. For all seasons and during low and medium solar activity, RSF is the most observed type of spread-F except in March equinox, when during medium solar activity FSF was the only type of spread-F observed.

RSF occurrence rate was higher during quiet geomagnetic activity $(A p<12)$ than during disturbed geomagnetic activity $(A p \geq 12)$ in all seasons except in June solstice (Figure 14). FSF was most seen under quiet geomagnetic conditions for September equinox and December solstice, and during disturbed conditions for June solstice and March equinox. SSF occurrence rate was higher under quiet geomagnetic conditions and was not observed during disturbed days of March equinox and June solstice. In March equinox, under disturbed conditions, the FSF occurrence rate was higher than the RSF occurrence rate. The opposite was observed in the other seasons.

\subsection{Plasma Bubbles occurrence rate}

As an example, Figure 15 shows TEC depletions along satellites Pseudorandom Numbers (PRNs) 27 and 16 arcs for 20/11/14. These plasma bubble signatures appeared at 22-1 LT, except in June solstice 2017 (0-3 LT) and December solstice 2018 (2-6 LT). We observed a high occurrence of plasma bubbles in the December solstice (summer in the Southern Hemisphere) and a low occurrence in the June solstice (winter in the Southern Hemisphere). We did not see any plasma bubbles in June solstice 2015 and 2018 (Figure 16a). 
There were no days with high solar activity in March and September equinox. During the June solstice, the days with high solar activity levels did not present TEC depletion. In all seasons, plasma bubble occurrence increased with the F10.7 index (Fig 16b). The period with the highest plasma bubble occurrence percentage was December solstice during high solar activity $(80 \%)$. Whereas the lowest occurrence was in the June solstice during low solar activity (0.4\%).

Under low solar activity levels (Fig 16c), plasma bubble occurrence enhanced on disturbed days in all seasons except in June solstice when no plasma bubble was observed. Under medium solar activity (Figure 16d), plasma bubble occurrence rate increased with geomagnetic activity in all seasons but in December solstice. For the latter, plasma bubble occurrence during quiet days (38.7\%) was higher than during disturbed days (29.4\%).

\section{Discussion}

This study shows that RSF was the most common type of spread-F over Tucumán during the descending phase of Solar Cycle 24, it frequently developed around midnight (except during June solstice when its occurrence peaked later) whereas FSF events usually occurred after midnight. SSF was sparse and mostly seen during the December solstice. We observed the highest occurrence rate of plasma bubble (TEC depletion) and RSF during local summer for all solar and geomagnetic conditions except in 2018 when RSF occurrence peaked in winter. Plasma bubble and spread-F occurrences were minimum in winter and equinox, respectively. Spread-F events lasted less than three hours and did not exhibit any seasonal trend. Spread-F occurrence rate decreased with solar activity, with two exceptions: RSF in September equinox and SSF in December solstice. The plasma bubble occurrence rate was positively correlated with solar activity. Whereas, the response of spread-F occurrence to geomagnetic activity varied with the season: it decreased under disturbed conditions during all seasons except in June solstice when the opposite was observed. FSF occurrence slightly increased under disturbed conditions in March equinox. The plasma bubble occurrence rate was higher on disturbed days than in quiet days with the exception of December solstice under medium solar activity. In this period we saw more plasma bubbles during quiet geomagnetic conditions than during disturbed conditions.

The plasma bubble seasonal variation pattern observed in the present work-high occurrence during local summer and low occurrence during winter-agree with previous studies carried out in South America (Abdu et al. 1998; Sahai et al. 1994). The occurrence of irregularities maximizes when sunset at the conjugate E-regions is nearly simultaneous, that is when the sunset terminator is aligned with the magnetic meridian (Abdu et al. 1981; Tsunoda 1985). In Tucumán, the magnetic declination angle is $\sim 7^{\circ} \mathrm{W}$ and close alignment occurs in the summer solstice. The spread-F occurrence was maximum in December solstice and minimum in equinox, in coincidence with the observations of Dabas et al. (2007) at a low latitude station in the Indian region. Also, our results evince a solstice asymmetry that is, higher occurrence rates in the December solstice than in the June solstice. Nishioka et al. (2008) proposed that the seasonal variation of the flux tube integrated conductivities in the F-regions could partially explain this behaviour. 
Our observation of a positive correlation between Plasma bubble occurrence and solar activity agrees with previous studies (Abdu et al. 1985; Sahai et al. 2000; Shetti et al. 2019). Regarding spread-F, some researchers reported a negative correlation with the F10.7 index. Wang et al. (2019) observed that the FSF occurrence percentages were higher during the low solar activity years at mid-latitudes in Eastern Asia. Wang et al. (2018) found similar results with data from four ionosondes at low- and mid-latitudes in China. Balan et al. (2018) concluded that at low latitudes in Japan, spread-F was most frequent under low solar activity. On the other hand, some studies disagree with these observations. Klinngam et al. (2015) studied the spread-F occurrence in Southeast Asia, they showed that the percentage of RSF occurrence increased with the level of solar activity, while the FSF occurrence decreased. Thammavongsy et al. (2020) studied the spread-F occurrence percentage during the peak of solar cycle 24 at Chumphon station, Thailand. They concluded that the tendency of the RSF occurrence rate was proportional to the F10.7 solar flux. We show herein that spread-F occurrence decreased with solar flux in all seasons, except for RSF in September equinox and SSF in December solstice. Unfortunately, we did not study the spread-F under high solar activity (F10.7 $\geq 180$ ) because of the lack of ionosonde data. The disparity in the results reported in the literature highlights the complexity of this ionospheric phenomenon. The difference in the observations may be related to the effects of the thermospheric zonal wind and the atmospheric waves that alter the primary parameters important for spread-F formation.

During June solstice, RSF occurrence steadily increased from 2015 to 2018 (when the occurrence rate reached over $80 \%$ ) as the mean F10.7 index decreased. However, plasma bubbles were very few in June solstice (less than 2.3\%) and were absent in 2015 and 2018 during this season, as seen from TEC depletions. At low latitudes, RSF in ionograms usually indicates plasma bubbles originated around sunset at the magnetic equator that expanded to higher latitudes along the magnetic field lines (Abdu et al. 1998). To be detected in Tucumán, the strength of the equatorial evening $E \times B$ drift (due to the prereversal enhancement, PRE) should be strong enough for the bubble to reach a high apex altitude over the magnetic equator. Previous studies attributed the low plasma bubble occurrence during June solstice to a weak equatorial electric field pre-reversal enhancement over South America (Batista et al., 1996; Fejer et al. 1999). Sahai et al. (2000) analysed the Ol $630 \mathrm{~nm}$ all-sky imaging data from Cachoeira Paulista, Brazil (a location at the southern crest of the EIA) and found that plasma bubbles attaining high apex heights $(\geq 1500 \mathrm{~km}$ ) at the magnetic equator were more abundant during high solar activity $(66 \%)$ compared with low solar activity (34\%). Lee et al. (2009) investigated the occurrence of $\mathrm{F}$ region irregularities at the EIA crest during solar maximum and concluded that the possibility for irregularities to extend from the dip equator to the EIA crest was about $50 \%$. So it is reasonable to think that the RSF observed in the June solstice during low solar activity may be associated with other phenomena rather than plasma bubbles.

During low solar activity and quiet geomagnetic conditions, and when the PRE is small (as in June solstice), the gravity waves may play a significant role in the spread-F seeding process. Candido et al. (2011) reported a low occurrence of spread-F during June solstice at high solar activity years and a progressive increase during moderate and low solar flux conditions at Cachoeira Paulista. They observed a frequent occurrence of spread-F in June solstice during solar minimum activity and mainly under quiet geomagnetic conditions. They suggested that these events could be caused by ionospheric disturbances 
unrelated to equatorial processes such as travelling ionospheric disturbances (TIDs) from mid-latitudes. Deng et al. (2021) pointed out that medium-scale TIDs associated with Perkins instability likely trigger spread-F at low latitudes in South America. Cabrera et al. (2010) evaluated the RSF day-to-day variability in September 2007 (low solar activity) at Tucumán. They argued that locally generated plasma instabilities related to gravity waves triggered by the solar terminator could cause RSF rather than plasma bubbles coming from the magnetic equator. Pezzopane et al. (2013) analysed four equinoctial months in a year of low solar activity and found that satellite traces caused by gravity waves propagation are a precursor to the RSF appearance at Tucumán. Alfonsi et al. (2013) studied ionosonde data from Tucumán during October 2010 to September 2011. They concluded that exist a connection between RSF occurrence and medium-scale TIDs due to gravity wave propagation. Afolayan et al. (2019) attributed the large RSF occurrence percentage during low solar activity in the West African region to the presence of gravity waves. Furthermore, the amplitude of the gravity wave seed perturbation decides whether spread$F$ would form. The neutral density decreases as the solar flux decreases, so lower seed magnitude for spread-F occurrence is needed as solar activity decreases (Manju et al. 2016). We suggest that the RSF signatures seen in the ionograms in Tucumán during winter in low solar activity may be related to TIDs.

Under medium solar activity, we observed that during the high plasma bubbles occurrence season (December solstice, summer in the Southern Hemisphere), days with disturbed geomagnetic activity registered fewer TEC depletions. Whereas, in the low plasma bubbles occurrence season (June solstice, winter in the Southern Hemisphere), the plasma bubble occurrence rate was higher during disturbed conditions. These results agree with Becker-Guedes et al. (2004) who proposed that geomagnetic activity inhibits plasma bubbles generation during high plasma bubbles occurrence season, and helps in the initiation process during low occurrence season. Timoçin et al. (2020) investigated the behaviour of plasma bubble irregularities under different geomagnetic conditions during March 2015 and September 2017 at three low latitudes stations. They observed that the plasma bubble occurrence rate increased with geomagnetic activity, in concordance with our results.

Regarding the response of RSF, FSF and SSF to geomagnetic activity, we generally observed a suppression during equinox and summer but an enhancement during winter. Our results are partially consistent with those of Whalen (2002), who used an array of ionospheric sounders in the western American sector during solar maximum and showed that spread-F decrease with increasing Kp during equinox and summer, but they found no correlation in winter. Lan et al. (2019) analysed ionograms recorded at the northern equatorial ionization anomaly in China. They reported a positive correlation for all types of spread-F in winter, an inverse correlation for SSF during equinox and summer, and for FSF in summer. Whereas RSF increases with geomagnetic activity in all seasons. We observed similar results except for RSF that according to our data was negatively correlated with geomagnetic activity in all seasons except in June solstice.

Spread-F suppression/generation may be a consequence of the effect of the magnetic activity on the $E \times B$ velocity, hence in the vertical growth of the irregularities. Electric field perturbations associated with the solar wind-magnetosphere dynamo or with the ionospheric disturbance dynamo (Blanc \& Richmond 
1980; Senior \& Blanc 1984) can significantly modify the low-latitude electric fields during disturbed geomagnetic conditions. Depending upon their local time-dependent polarity, these disturbance electric fields could increase the plasma vertical drift-because of a stronger eastward electric field-and uplift the $\mathrm{F}$ layer to heights with reduced collision frequency and thus enhance the instability growth. $\mathrm{A}$ westward disturbance electric field can cause plasma downdraft and a drop in the F layer height that may induce a suppression or disruption in the irregularity development. Therefore, the response of spread-F to geomagnetic activity depends on the location of the station, the season, and the phase of the storm.

The vertical plasma drift and the ensuing $\mathrm{F}$ layer uplift are important conditions for the development of ionospheric irregularities. Thus, ionospheric parameters e.g. the virtual height of the $F$ layer bottom side ( $h$ 'F), the F layer peak height (hmF2) or the critical frequency of the F2 layer (foF2) are needed to further examine the precursor conditions that may lead to spread-F generation. With this in mind, we are developing software that allows us to get automatically these parameters from the VIPIR ionograms. Another basic condition to start the instability growth is a source of density perturbations, such as gravity waves. To further study the role of these seed perturbations on the day-to-day variability of spread-F, case studies combining ground-based and space-borne observations are required.

\section{Conclusion}

We analysed the RSF, FSF, SSF and TEC depletion occurrence at Tucumán, a station near the southern crest of the EIA during the descending phase of Solar Cycle 24. The main outcomes of this work are:

1. RSF was the most frequent type of spread-F in Tucumán.

2. Spread-F and plasma bubble occurrence rates were maximum in local summer, but in 2018 the highest RSF occurrence was in winter.

3. Plasma bubble and spread-F occurrence rates were minimum in winter and equinox, respectively.

4. Spread-F decreased with solar activity, except for RSF in September equinox and SSF in December solstice when we observed a positive correlation.

5. Plasma bubble occurrence increased with solar activity in all seasons.

6. RSF, FSF and SSF occurrence generally decreased under disturbed geomagnetic conditions in equinox and December solstice. Whereas it increased in June solstice.

7. Under low solar activity, there is a positive correlation between plasma bubble occurrence and geomagnetic activity. Whereas, under medium solar activity, there was a negative correlation in December solstice and a positive one in all the other seasons.

8. RSF signatures observed in winter under low solar activity were not related to plasma bubbles originated at the magnetic equator. A possibility is that these irregularities were associated with travelling ionospheric disturbances. This needs to be further analysed.

\section{Declarations}


Acknowledgment The author thanks the following groups for making the data available: The Low Latitude lonospheric Sensor Network (LISN), Royal Observatory of Belgium, National Research Council Canada, and the GFZ German Research Centre for Geosciences.

\section{References}

Abdu, M. A., Bittencourt, J. A., \& Batista, I. S. (1981). Magnetic declination control of the equatorial F region dynamo electric field development and spread F. Journal of Geophysical Research, 86(A13), 11443. https://doi.org/10.1029/JA086iA13p11443

Abdu, M. ., Sobral, J. H. ., Nelson, O. ., \& Batista, I. . (1985). Solar cycle related range type spread-F occurrence characteristics over equatorial and low latitude stations in Brazil. Journal of Atmospheric and Terrestrial Physics, 47(8-10), 901-905. https://doi.org/10.1016/0021-9169(85)90065-0

Abdu, M. A., Sobral, J. H. A., Batista, I. S., Rios, V. H., \& Medina, C. (1998). Equatorial spread-F occurrence statistics in the American longitudes: Diurnal, seasonal and solar cycle variations. Advances in Space Research, 22(6), 851-854. https://doi.org/10.1016/S0273-1177(98)00111-2

Abdu, M. A., Souza, J. R., Batista, I. S., \& Sobral, J. H. A. (2003). Equatorial spread F statistics and empirical representation for IRI: A regional model for the Brazilian longitude sector. Advances in Space Research, 31(3), 703-716. https://doi.org/10.1016/S0273-1177(03)00031-0

Abdu, M. A., Kherani, E. A., \& Sousasantos, J. (2020). Role of Bottom-Side Density Gradient in the Development of Equatorial Plasma Bubble/Spread F Irregularities: Solar Minimum and Maximum Conditions. Journal of Geophysical Research: Space Physics, 125(10), 0-3.

https://doi.org/10.1029/2020JA027773

Afolayan, A. O., Jit Singh, M., Abdullah, M., Buhari, S. M., Yokoyama, T., \& Supnithi, P. (2019). Observation of seasonal asymmetry in the range spread $\mathrm{F}$ occurrence at different longitudes during low and moderate solar activity. Annales Geophysicae, 37(4), 733-745. https://doi.org/10.5194/angeo-37-733-2019

Alfonsi, L., Spogli, L., Tong, J. R., De Franceschi, G., Romano, V., Bourdillon, A., ... Mitchell, C. N. (2011). GPS scintillation and TEC gradients at equatorial latitudes in April 2006. Advances in Space Research, 47(10), 1750-1757. https://doi.org/10.1016/j.asr.2010.04.020

Alfonsi, L., Spogli, L., Pezzopane, M., Romano, V., Zuccheretti, E., De Franceschi, G., ... Ezquer, R. G. (2013). Comparative analysis of spread-F signature and GPS scintillation occurrences at Tucumán, Argentina. Journal of Geophysical Research: Space Physics, 118(7), 4483-4502. https://doi.org/10.1002/jgra.50378 
Aquino, M., \& Sreeja, V. (2013). Correlation of scintillation occurrence with interplanetary magnetic field reversals and impact on global navigation satellite system receiver tracking performance. Space Weather, 11(5), 219-224. https://doi.org/10.1002/swe.20047

Batista, I. S., de Medeiros, R. T., Abdu, M. A., de Souza, J. R., Bailey, G. J., \& de Paula, E. R. (1996). Equatorial ionospheric vertical plasma drift model over the Brazilian region. Journal of Geophysical Research: Space Physics, 101(A5), 10887-10892. https://doi.org/10.1029/95JA03833

Becker-Guedes, F., Sahai, Y., Fagundes, P. R., Lima, W. L. C., Pillat, V. G., Abalde, J. R., \& Bittencourt, J. A. (2004). Geomagnetic storm and equatorial spread-F. Annales Geophysicae, 22(9), 3231-3239. https://doi.org/10.5194/angeo-22-3231-2004

Beshir, E., Nigussie, M., \& Moldwin, M. B. (2020). Characteristics of equatorial nighttime spread F - An analysis on season-longitude, solar activity and triggering causes. Advances in Space Research, 65(1), 95-106. https://doi.org/10.1016/j.asr.2019.09.020

Booker, G., \& Wells, H. W. (1938). Scattering of radio waves by the F-region of the ionosphere. Journal of Geophysical Research, 43, 249-256. Retrieved from https://agupubs.onlinelibrary.wiley.com/doi/abs/10.1029/TE043i003p00249

Bowman, G. G., \& Mortimer, I. K. (2003). Influence of geomagnetic activity on the occurrence of midlatitude ionogram-recorded spread-F. Indian Journal of Radio and Space Physics, 32(1), 16-20.

Bullett, T. (2008). Station Report: A new ionosonde at Boulder. Retrieved from https://www.sws.bom.gov.au/IPSHosted/INAG/web-69/2008/boulder_vipir.pdf

Cabrera, M. A., Pezzopane, M., Zuccheretti, E., \& Ezquer, R. G. (2010). Satellite traces, range spread-F occurrence, and gravity wave propagation at the southern anomaly crest. Annales Geophysicae, 28(5), 1133-1140. https://doi.org/10.5194/angeo-28-1133-2010

Candido, C. M. N., Batista, I. S., Becker-Guedes, F., Abdu, M. A., Sobral, J. H. A., \& Takahashi, H. (2011). Spread $\mathrm{F}$ occurrence over a southern anomaly crest location in Brazil during June solstice of solar minimum activity. Journal of Geophysical Research: Space Physics, 116(6), 2008-2009. https://doi.org/10.1029/2010JA016374

Çepni, M. S., Potts, L. V., \& Miima, J. B. (2013). High-resolution station-based diurnal ionospheric total electron content (TEC) from dual-frequency GPS observations. Space Weather, 11(9), 520-528. https://doi.org/10.1002/swe.20093

Chum, J., Liu, J. Y., Chen, S. P., Cabrera, M. A., Laštovička, J., Baše, J., ... Ezquer, R. (2016). Spread F occurrence and drift under the crest of the equatorial ionization anomaly from continuous Doppler sounding and FORMOSAT-3/COSMIC scintillation data. Earth, Planets and Space, 68(1), 1-18. https://doi.org/10.1186/s40623-016-0433-1 
Cueva, R. Y. C., De Paula, E. R., \& Kherani, A. E. (2013). Statistical analysis of radar observed F region irregularities from three longitudinal sectors. Annales Geophysicae, 31(12), 2137-2146. https://doi.org/10.5194/angeo-31-2137-2013

Dabas, R. S., Das, R. M., Sharma, K., Garg, S. C., Devasia, C. V., Subbarao, K. S. V., ... Rama Rao, P. V. S. (2007). Equatorial and low latitude spread-F irregularity characteristics over the Indian region and their prediction possibilities. Journal of Atmospheric and Solar-Terrestrial Physics, 69(6), 685-696. https://doi.org/10.1016/j.jastp.2007.01.002

DasGupta A., B. S. A. J. K. J. A. B. S. B. A., DasGupta, A., Basu, S. S., Aarons, J., Klobuchar, J. A., \& Bushby, A. (1983). VHF amplitude scintillations and associated electron content depletions as observed at Arequipa, Peru. Journal of Atmospheric and Terrestrial Physics, 45(1), 15-19,21-26. Retrieved from http://www.sciencedirect.com/science/article/pii/S0021916983800038

Dashora, N., \& Pandey, R. (2005). Observations in equatorial anomaly region of total electron content enhancements and depletions. Annales Geophysicae, 23(7), 2449-2456. https://doi.org/10.5194/angeo23-2449-2005

Deng, Z., Wang, R., Liu, Y., Xu, T., Wang, Z., Chen, G., ... Zhou, C. (2021). Investigation of Low Latitude Spread-F Triggered by Nighttime Medium-Scale Traveling Ionospheric Disturbance. Remote Sensing, 13(5), 945. https://doi.org/10.3390/rs13050945

Fejer, B. G., Scherliess, L., \& de Paula, E. R. (1999). Effects of the vertical plasma drift velocity on the generation and evolution of equatorial spread F. Journal of Geophysical Research: Space Physics, 104(A9), 19859-19869. https://doi.org/10.1029/1999JA900271

Kelley, M. C. (2009). The Earth's Ionosphere: Plasma Physics and Electrodynamics. International geophysics series; v. 96 (Second edition). Retrieved from https://www.sciencedirect.com/bookseries/international-geophysics/vol/96/suppl/C

Klinngam, S., Supnithi, P., Rungraengwajiake, S., Tsugawa, T., Ishii, M., \& Maruyama, T. (2015). The occurrence of equatorial spread-F at conjugate stations in Southeast Asia. Advances in Space Research, 55(8), 2139-2147. https://doi.org/10.1016/j.asr.2014.10.003

Kotulak, K., Zakharenkova, I., Krankowski, A., Cherniak, I., Wang, N., \& Fron, A. (2020). Climatology Characteristics of Ionospheric Irregularities Described with GNSS ROTI. Remote Sensing, 12(16), 2634. https://doi.org/10.3390/rs12162634

Lan, T., Jiang, C., Yang, G., Zhang, Y., Liu, J., \& Zhao, Z. (2019). Statistical analysis of low-latitude spread F observed over Puer, China, during 2015-2016. Earth, Planets and Space, 71(1), 138.

https://doi.org/10.1186/s40623-019-1114-7 
Lee, C. C., Chu, F. D., Chen, W. S., Liu, J. Y., Su, S.-Y., Liou, Y. A., \& Yu, S. B. (2009). Spread F, GPS phase fluctuations, and plasma bubbles near the crest of equatorial ionization anomaly during solar maximum. Journal of Geophysical Research: Space Physics, 114(A8), n/a-n/a.

https://doi.org/10.1029/2009JA014195

Li, Q., Zhu, Y., Fang, K., \& Fang, J. (2020). Statistical Study of the Seasonal Variations in TEC Depletion and the ROTI during 2013-2019 over Hong Kong. Sensors, 20(21), 6200.

https://doi.org/10.3390/s20216200

Magdaleno, S., Herraiz, M., \& de la Morena, B. A. (2012). Characterization of equatorial plasma depletions detected from derived GPS data in South America. Journal of Atmospheric and Solar-Terrestrial Physics, 74, 136-144. https://doi.org/10.1016/j.jastp.2011.10.014

Manju, G., Madhav Haridas, M. K., \& Aswathy, R. P. (2016). Role of gravity wave seed perturbations in ESF day-to-day variability: A quantitative approach. Advances in Space Research, 57(4), 1021-1028.

https://doi.org/10.1016/j.asr.2015.12.019

Muella, M. T. A. H., Kherani, E. A., De Paula, E. R., Cerruti, A. P., Kintner, P. M., Kantor, I. J., ... Abdu, M. A. (2010). Scintillation-producing Fresnel-scale irregularities associated with the regions of steepest TEC gradients adjacent to the equatorial ionization anomaly. Journal of Geophysical Research: Space Physics, 115(3), 1-19. https://doi.org/10.1029/2009JA014788

Nishioka, M., Saito, A., \& Tsugawa, T. (2008). Occurrence characteristics of plasma bubble derived from global ground-based GPS receiver networks. Journal of Geophysical Research: Space Physics, 113(5), 112. https://doi.org/10.1029/2007JA012605

Pezzopane, M., Zuccheretti, E., Abadi, P., De Abreu, A. J., De Jesus, R., Fagundes, P. R., ... Ezquer, R. G. (2013). Low-latitude equinoctial spread-F occurrence at different longitude sectors under low solar activity. Annales Geophysicae, 31(2), 153-162. https://doi.org/10.5194/angeo-31-153-2013

Pietrella, M., Pezzopane, M., Fagundes, P. R., de Jesus, R., Supnithi, P., Klinngam, S., ... Cabrera, M. A. (2017). Equinoctial spread-F occurrence at low latitudes in different longitude sectors under moderate and high solar activity. Journal of Atmospheric and Solar-Terrestrial Physics, 164, 149-162. https://doi.org/10.1016/j.jastp.2017.07.007

Piggott, W. R., \& Rawer, K. (1978). Revision of Chapters 1-4 U.R.S.I. Handbook of lonogram Interpretation and Reduction. Report UAG-23A (Second). Boulder, Colorado: World Data Cent. A for Sol. Terr. Phys.

Reinisch, B. W., Abdu, M., Batista, I., Sales, G. S., Khmyrov, G., Bullett, T. A., ... Rios, V. (2004). Multistation digisonde observations of equatorial spread F in South America. Annales Geophysicae, 22(9), 31453153. https://doi.org/10.5194/angeo-22-3145-2004 
Sahai, Y., Aarons, J., Mendillo, M., Baumgardner, J., Bittencourt, J. A., \& Takahashi, H. (1994). OI 630 nm imaging observations of equatorial plasma depletions at $16^{\circ} \mathrm{S}$ dip latitude. Journal of Atmospheric and Terrestrial Physics, 56(11), 1461-1475. https://doi.org/10.1016/0021-9169(94)90113-9

Sahai, Y., Fagundes, P. R., \& Bittencourt, J. A. (2000). Transequatorial F-region ionospheric plasma bubbles: solar cycle effects. Journal of Atmospheric and Solar-Terrestrial Physics, 62(15), 1377-1383. https://doi.org/10.1016/S1364-6826(00)00179-6

Seemala, G. K., \& Valladares, C. E. (2011). Statistics of total electron content depletions observed over the South American continent for the year 2008. Radio Science, 46(5), 1-14. https://doi.org/10.1029/2011RS004722

Seker, I., Fung, S. F., \& Mathews, J. D. (2011). Relation between magnetospheric state parameters and the occurrence of plasma depletion events in the nighttime midlatitude F region. Journal of Geophysical Research: Space Physics, 116(4), 1-11. https://doi.org/10.1029/2010JA015521

Shetti, D. J., Gurav, O. B., \& Seemla, G. K. (2019). Occurrence characteristics of equatorial plasma bubbles and total electron content during solar cycle peak 23rd to peak 24th over Bangalore $(13.02 \circ \mathrm{N}, 77.57 \circ \mathrm{E})$. Astrophysics and Space Science, 364(9). https://doi.org/10.1007/s10509-019-3643-8

Shi, J. K., Wang, G. J., Reinisch, B. W., Shang, S. P., Wang, X., Zherebotsov, G., \& Potekhin, A. (2011). Relationship between strong range spread $F$ and ionospheric scintillations observed in Hainan from 2003 to 2007. Journal of Geophysical Research: Space Physics, 116(8), 1-5.

https://doi.org/10.1029/2011JA016806

Thammavongsy, P., Supnithi, P., Phakphisut, W., Hozumi, K., Tsugawa, T., \& Bannop, K. (2020). The Statistics of Equatorial Spread-F and Effects on Critical Frequency at Chumphon, Thailand. In Proceedings of the Sriwijaya International Conference on Information Technology and Its Applications (SICONIAN 2019) (Vol. 172, pp. 691-695). Paris, France: Atlantis Press.

https://doi.org/10.2991/aisr.k.200424.105

Timoçin, E., Inyurt, S., Temuçin, H., Ansari, K., \& Jamjareegulgarn, P. (2020). Investigation of equatorial plasma bubble irregularities under different geomagnetic conditions during the equinoxes and the occurrence of plasma bubble suppression. Acta Astronautica, 177(August), 341-350.

https://doi.org/10.1016/j.actaastro.2020.08.007

Tsunoda, R. T., \& Towle, D. M. (1979). On the spatial relationship of 1-meter equatorial spread-F irregularities and depletions in total electron content. Geophysical Research Letters, 6(11), 873-876. https://doi.org/10.1029/GL006i011p00873

Tsunoda, R. T. (1985). Control of the seasonal and longitudinal occurrence of equatorial scintillations by the longitudinal gradient in integrated E region Pedersen conductivity. Journal of Geophysical Research: Space Physics, 90(A1), 447-456. https://doi.org/10.1029/JA090iA01p00447 
Valladares, C. E., Villalobos, J., Sheehan, R., \& Hagan, M. P. (2004). Latitudinal extension of low-latitude scintillations measured with a network of GPS receivers. Annales Geophysicae, 22(9), 3155-3175. https://doi.org/10.5194/angeo-22-3155-2004

Yizengaw, E., \& Groves, K. M. (2018). Longitudinal and Seasonal Variability of Equatorial Ionospheric Irregularities and Electrodynamics. Space Weather, 16(8), 946-968.

https://doi.org/10.1029/2018SW001980

Yokoyama, T., Fukao, S., \& Yamamoto, M. (2004). Relationship of the onset of equatorial F region irregularities with the sunset terminator observed with the Equatorial Atmosphere Radar. Geophysical Research Letters, 31(24), 1-4. https://doi.org/10.1029/2004GL021529

Wakai, N., Ohyama, H., \& Koizumi, T. (1987). Manual of lonogram Scaling (Third Vers). Japan: Ministry of Posts and Telecommunications. Retrieved from

https://www.sws.bom.gov.au/IPSHosted/INAG/scaling/japanese_manual_v3.pdf

Weber, E. J., Basu, S., Bullett, T. W., Valladares, C., Bishop, G., Groves, K., ... Araya, J. (1996). Equatorial plasma depletion precursor signatures and onset observed at $11^{\circ}$ south of the magnetic equator. Journal of Geophysical Research: Space Physics, 101(A12), 26829-26838. https://doi.org/10.1029/96ja00440

Whalen, J. A. (2003). Dependence of the equatorial anomaly and of equatorial spread $f$ on the maximum prereversal E × B drift velocity measured at solar maximum. Journal of Geophysical Research: Space Physics, 108(A5), 1-9. https://doi.org/10.1029/2002JA009755

\section{Figures}




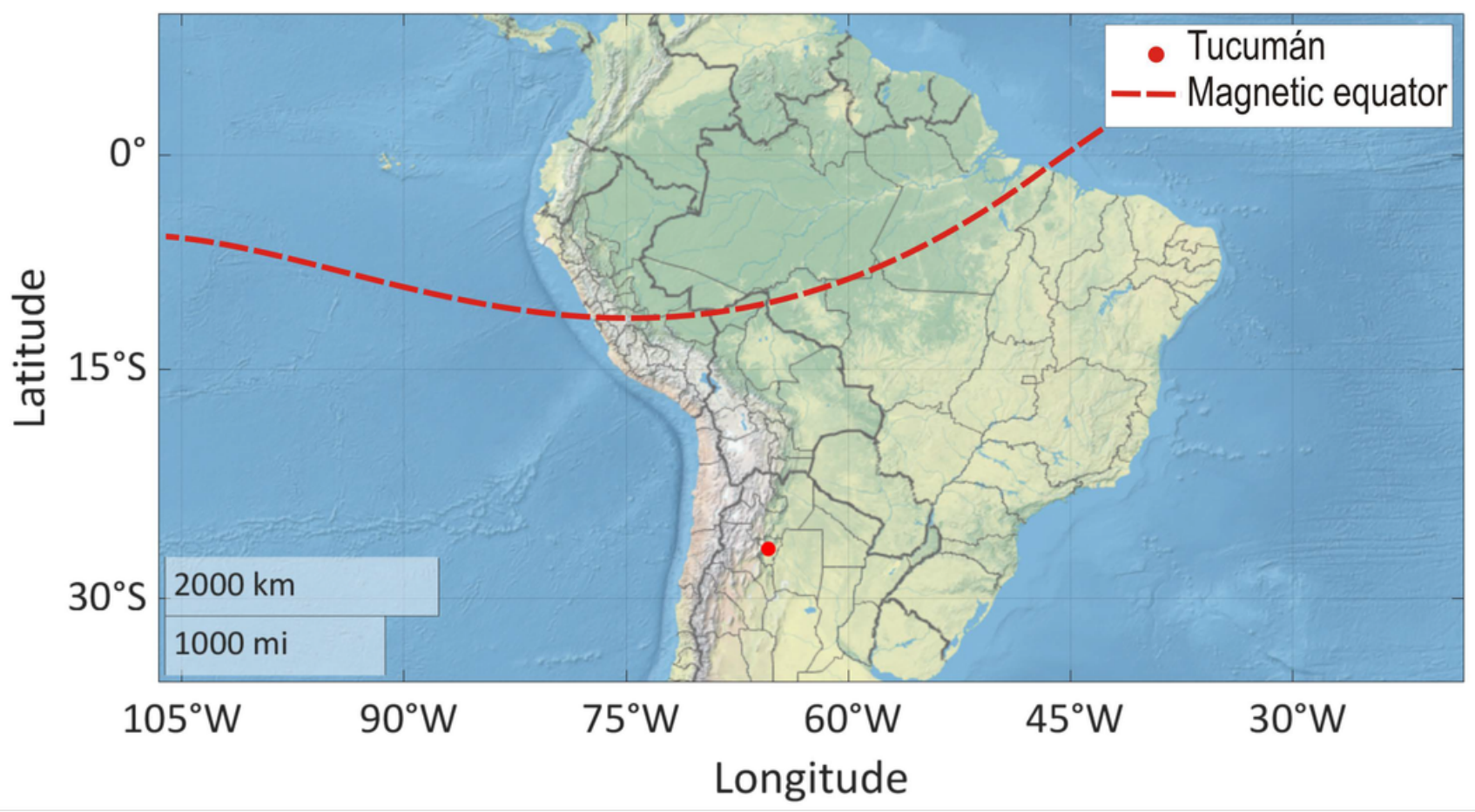

Figure 1

Map showing the location of Tucumán (red circle).

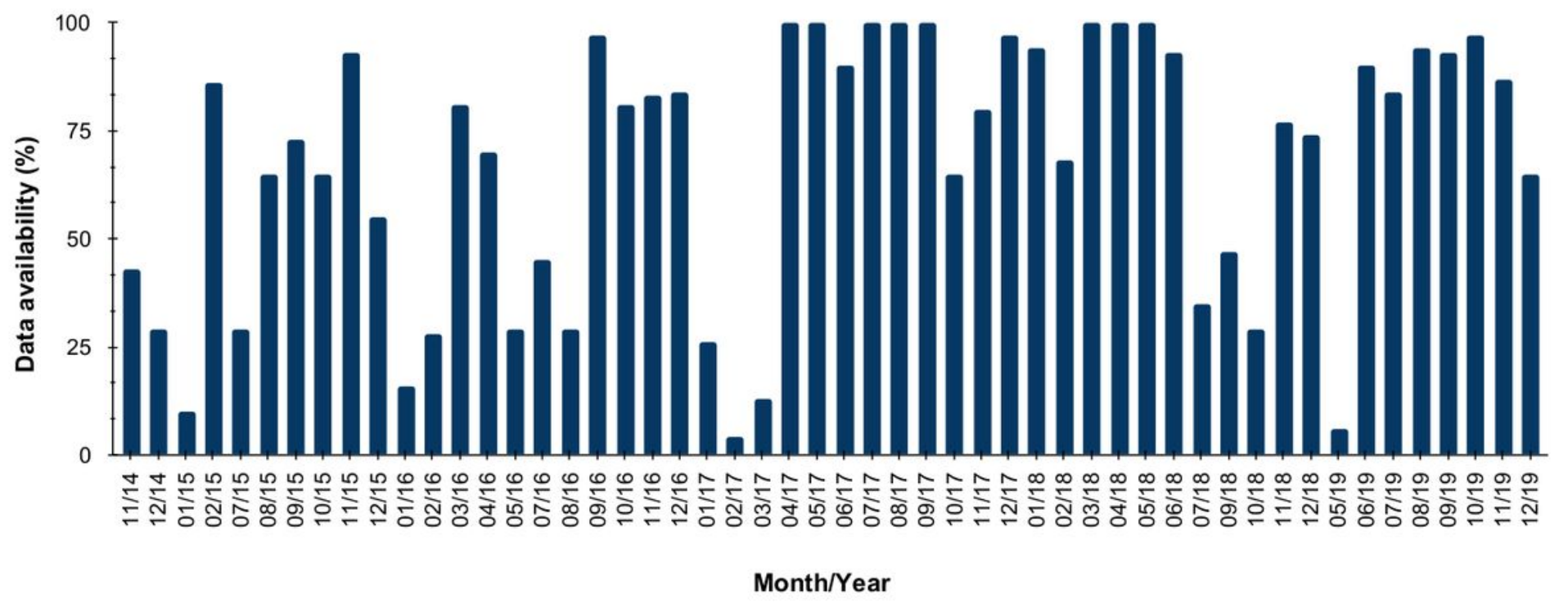

Figure 2

lonogram data availability per month in Tucumán station from November 2014 to December 2019. 

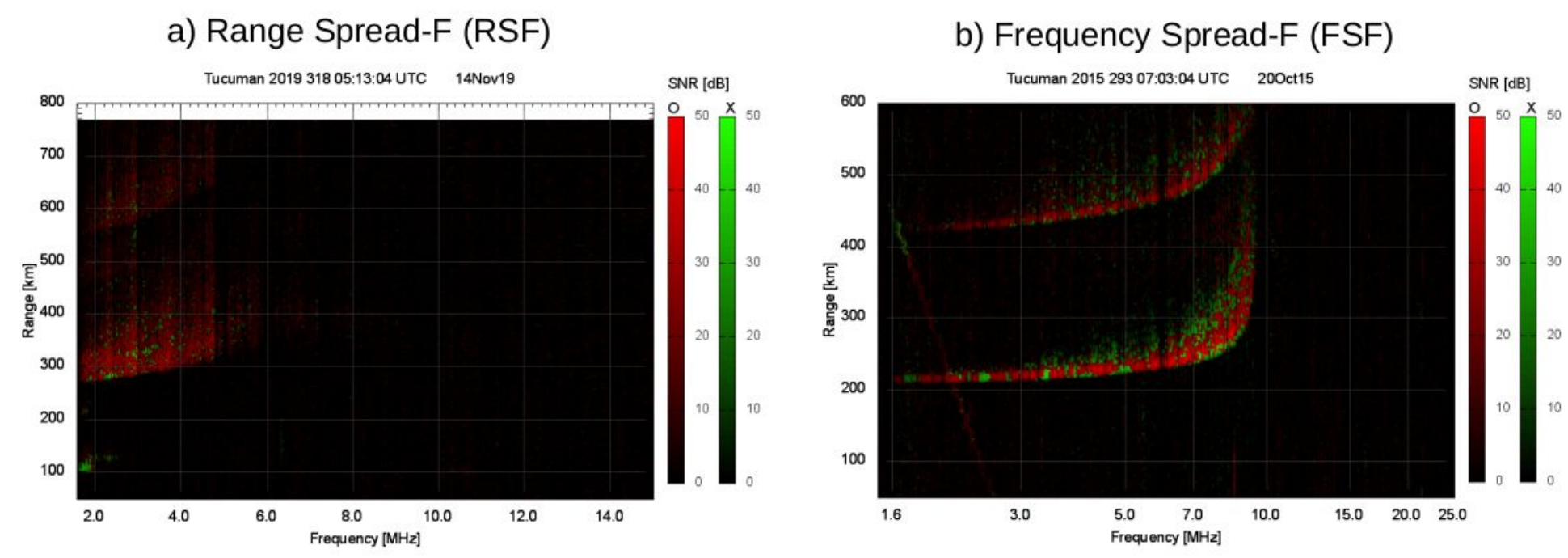

c) Strong range Spread-F (SSF)

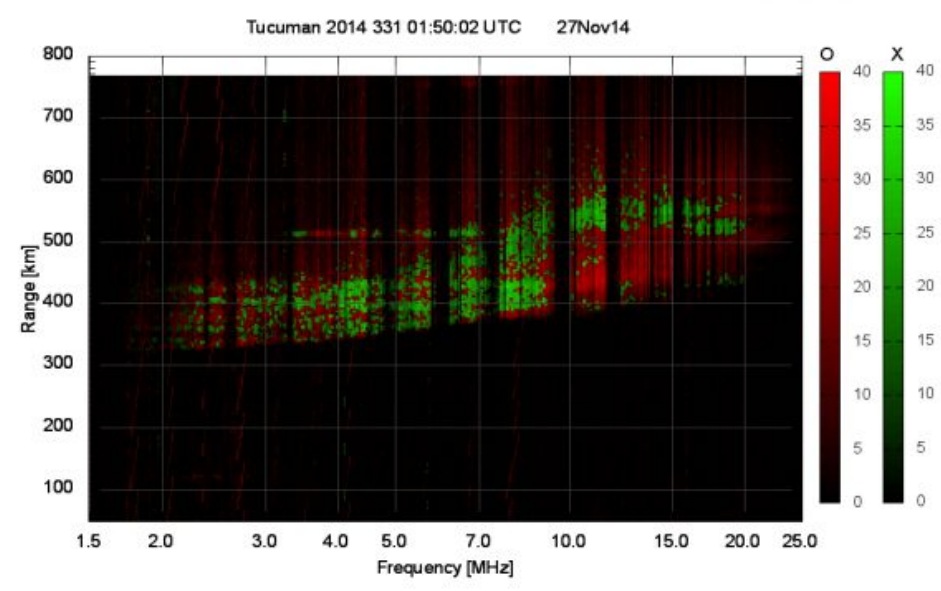

\section{Figure 3}

lonograms showing examples of (a) range spread-F (RSF) (b) frequency spread-F (FSF) and (c) strong range spread-F (SSF). 
a) Range Spread-F (RSF)
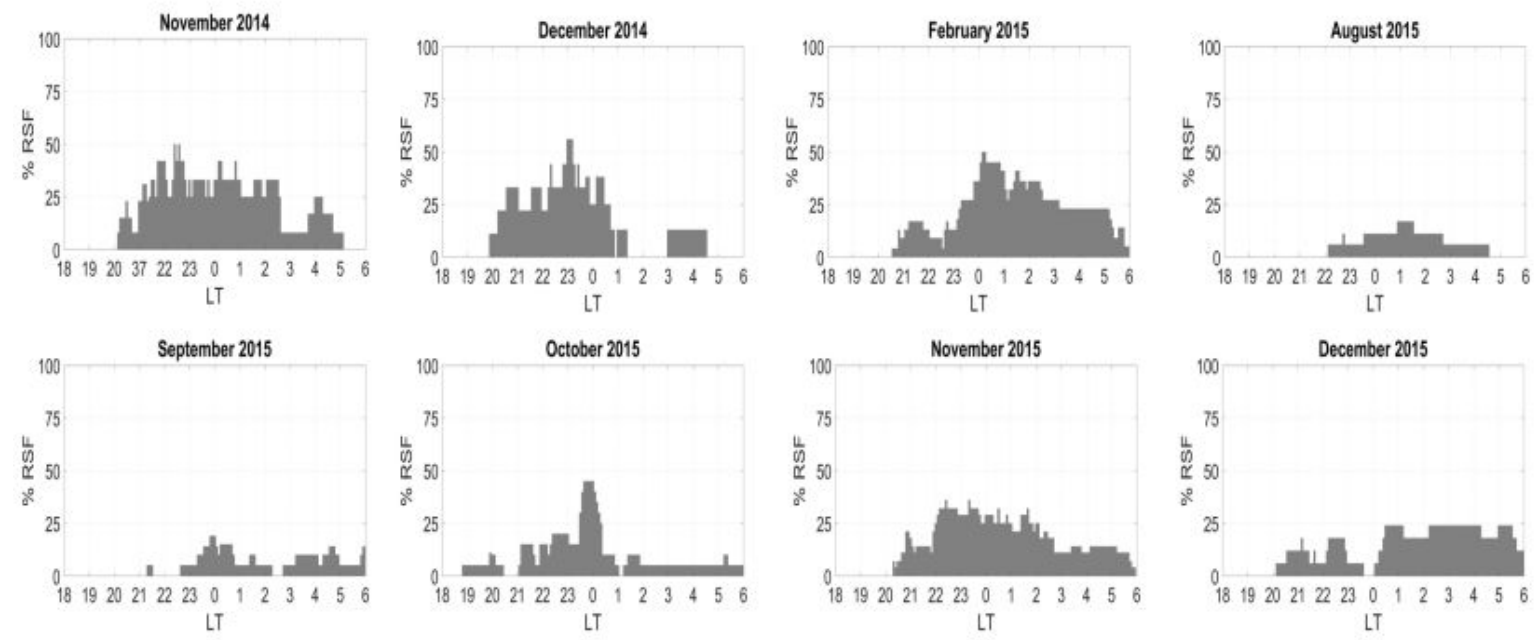

\section{b) Frequency Spread-F (FSF)}
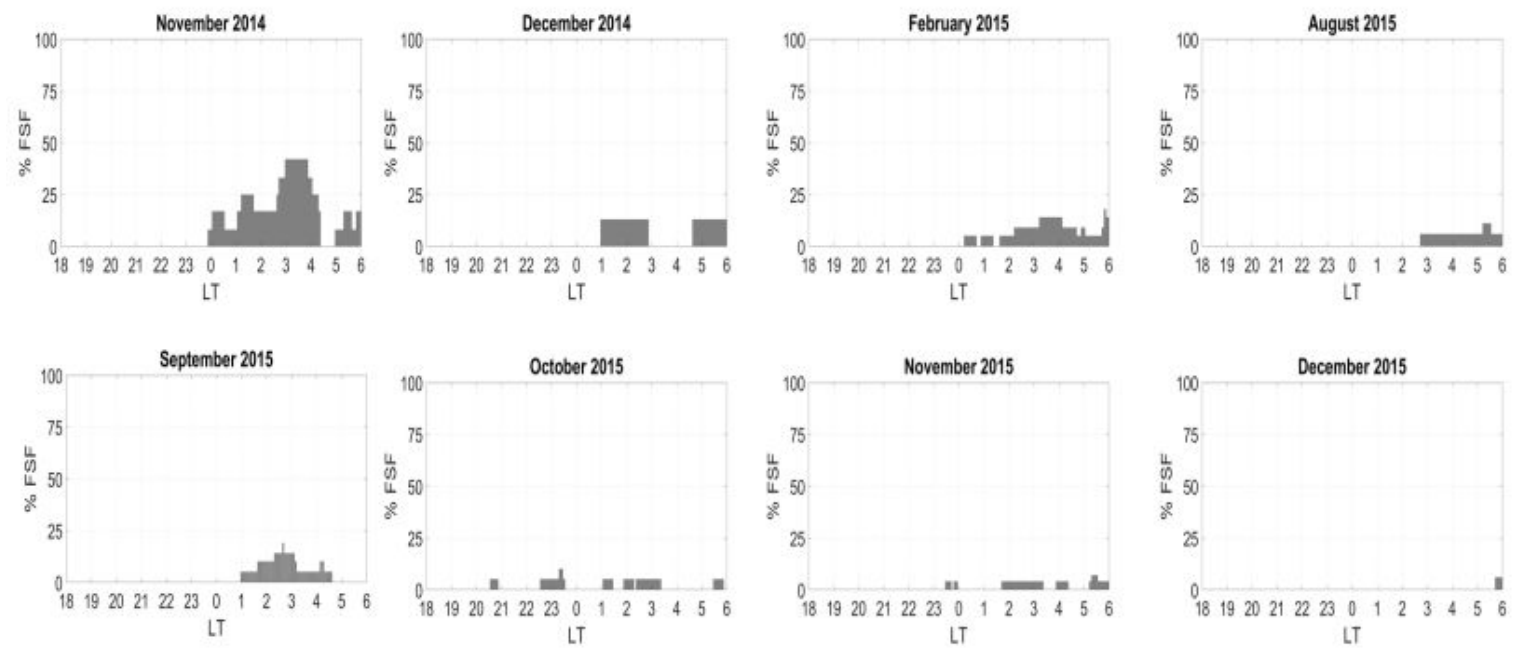

\section{c) Strong range Spread-F (SSF)}
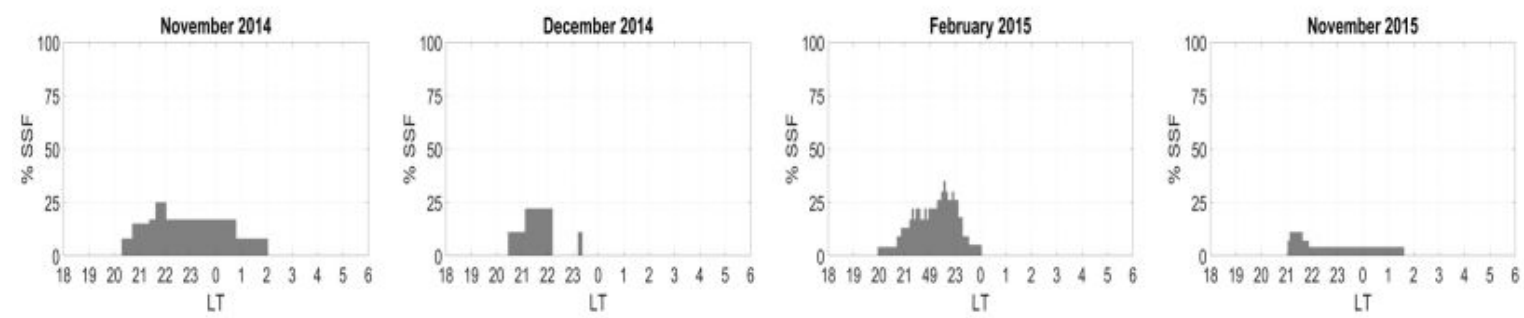

\section{Figure 4}

Monthly occurrence rate of a) range spread- $F(R S F), b)$ frequency spread-F (FSF) and c) strong range spread-F (SSF) over Tucumán station during November 2014 - December 2015. 
a) Range Spread-F (RSF)

\section{6}
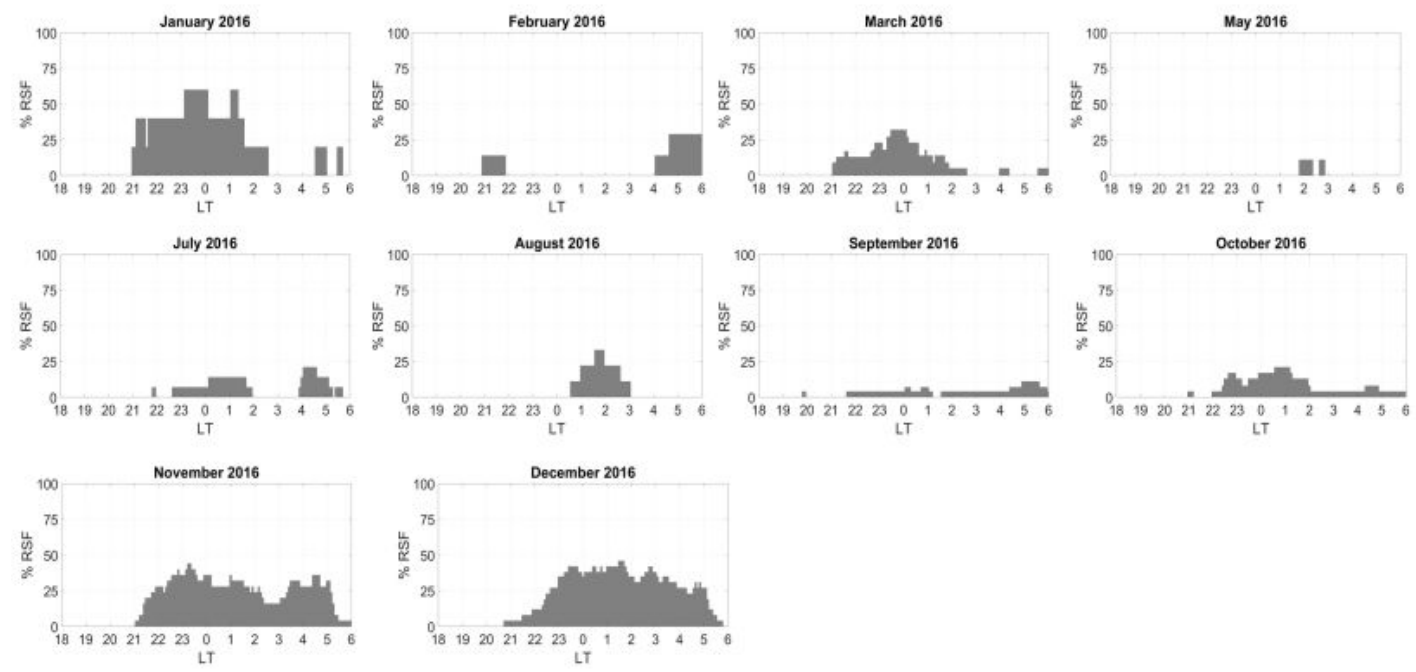

\section{b) Frequency Spread-F (FSF)}
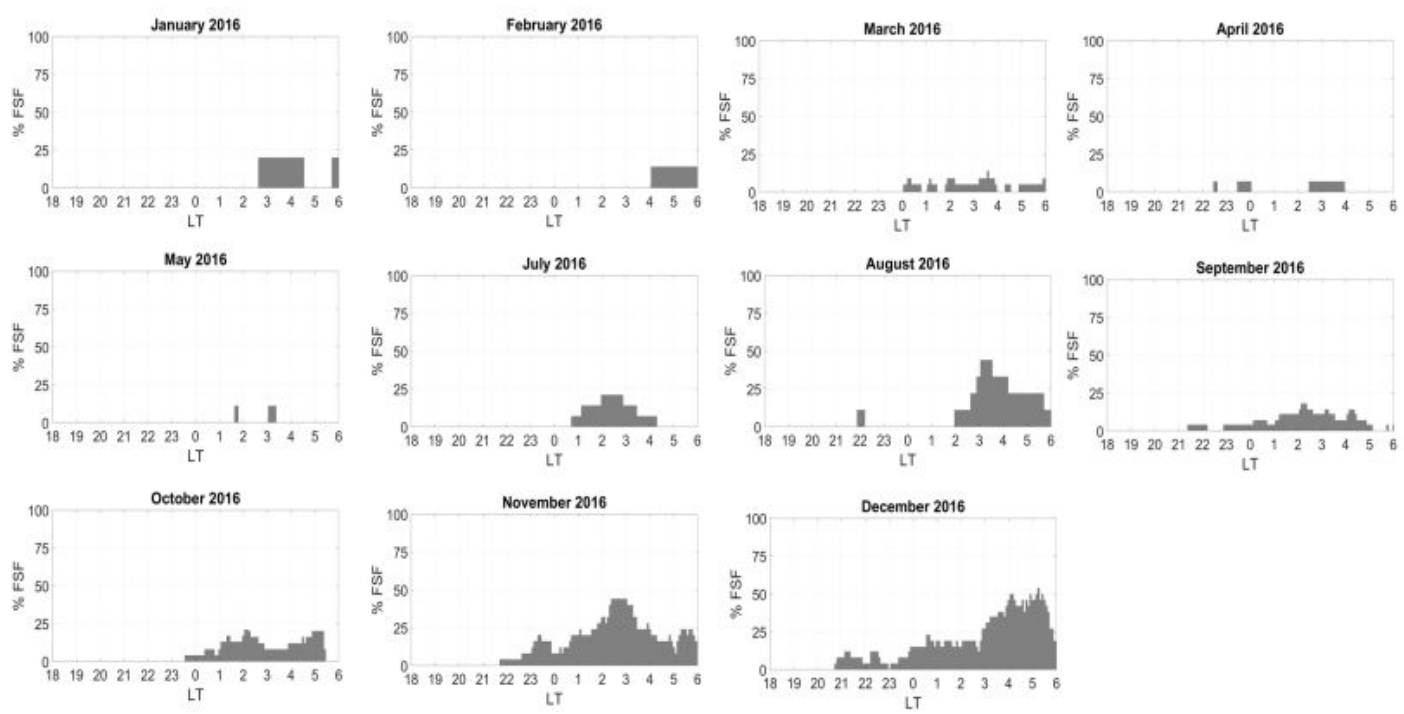

\section{c) Strong range Spread-F (SSF)}
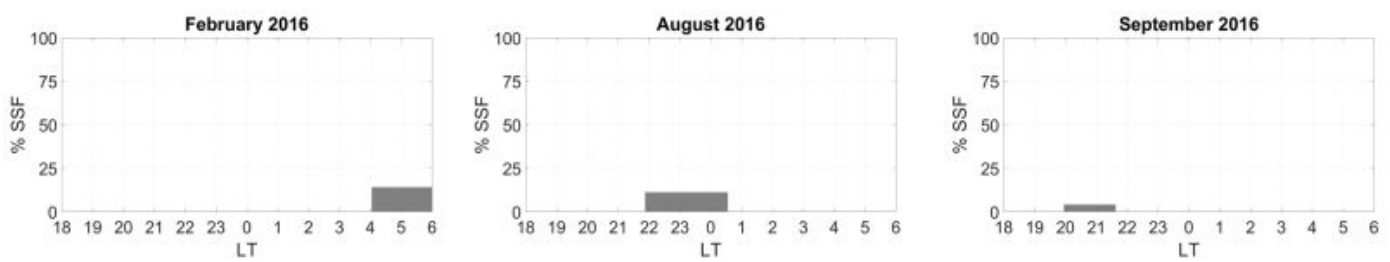

\section{Figure 5}

Monthly occurrence rate of a) range spread- $F(R S F), b)$ frequency spread- $F(F S F)$ and c) strong range spread-F (SSF) over Tucumán station during 2016. 
a) Range Spread-F (RSF)
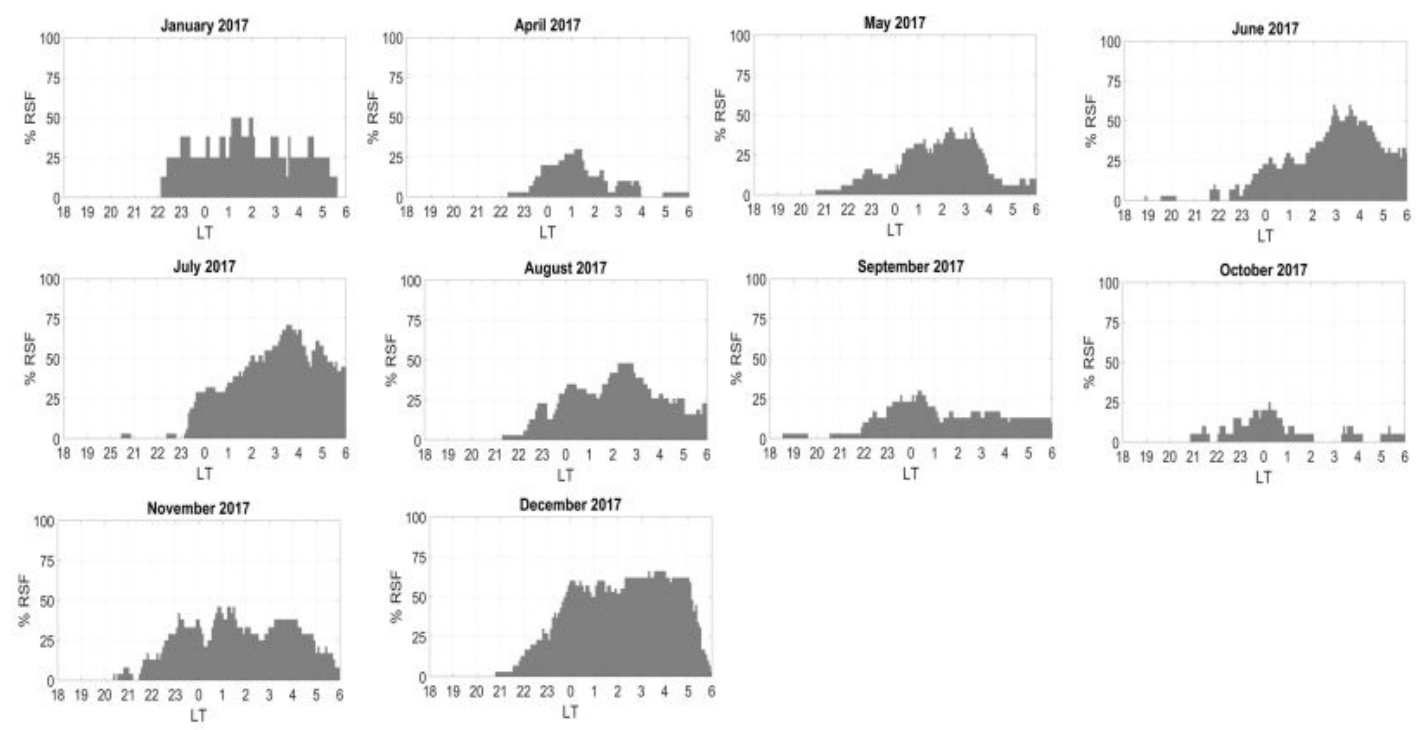

\section{b) Frequency Spread-F (FSF)}
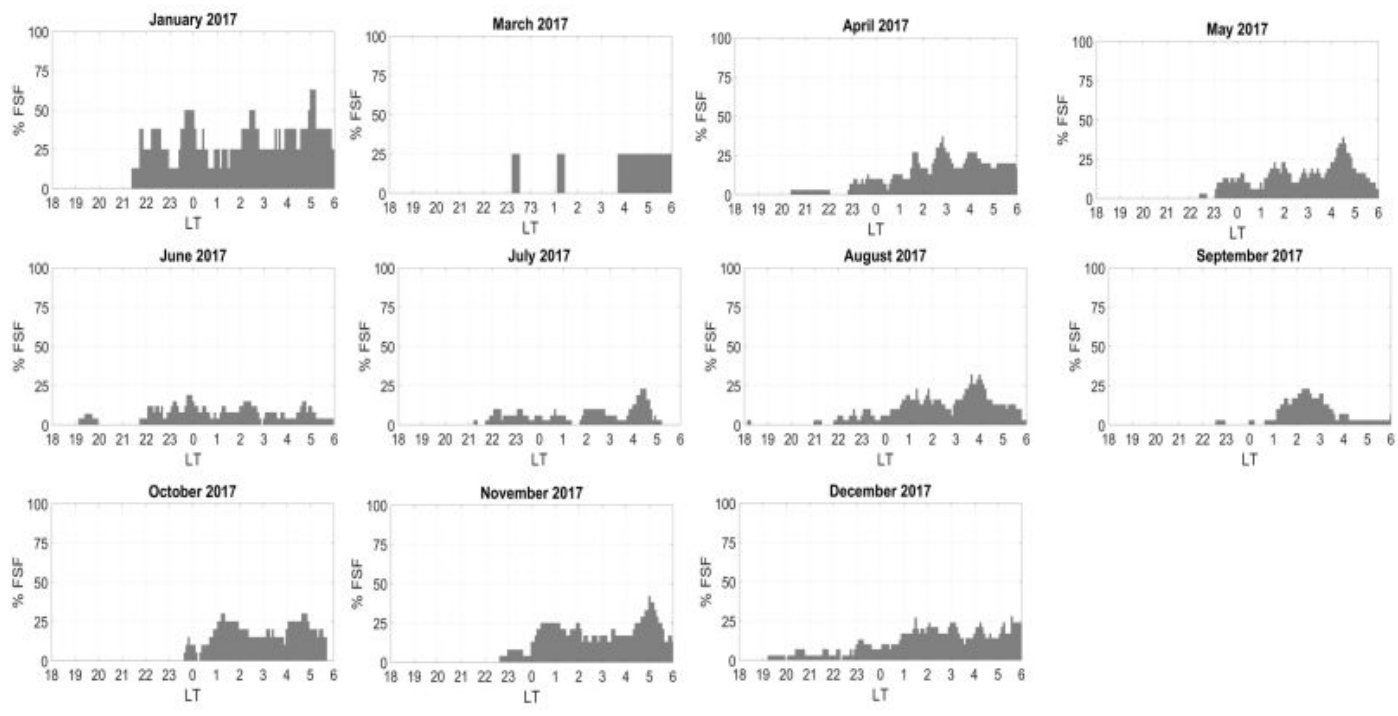

\section{c) Strong range Spread-F (SSF)}
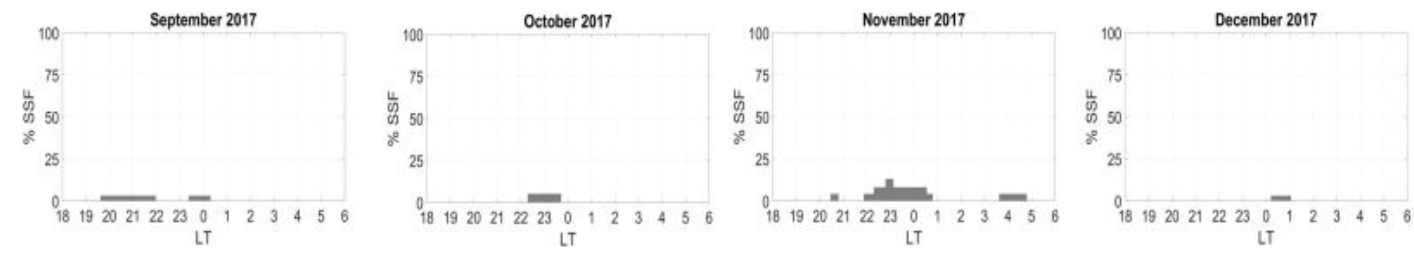

\section{Figure 6}

Monthly occurrence rate of a) range spread- $F(R S F), b$ ) frequency spread-F (FSF) and c) strong range spread-F (SSF) over Tucumán station during 2017. 
a) Range Spread-F (RSF)
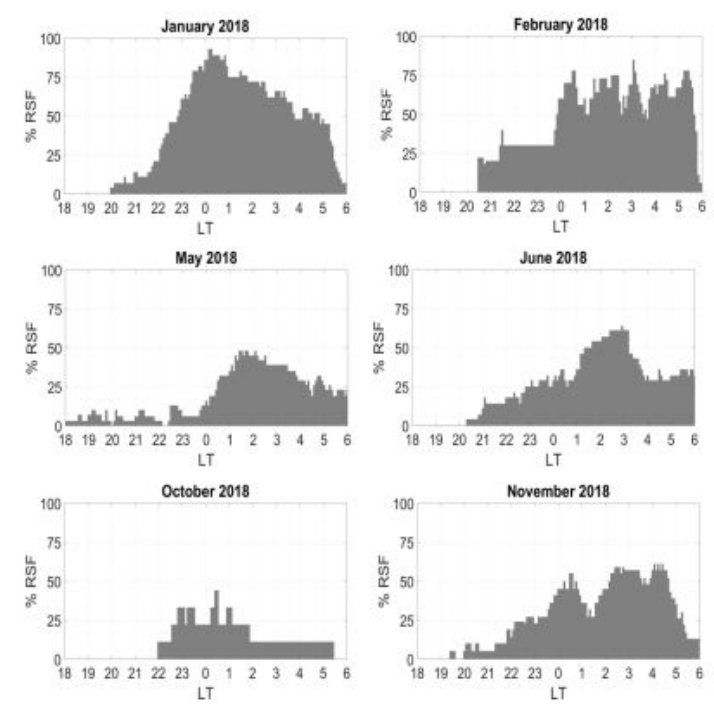

b) Frequency Spread-F (FSF)
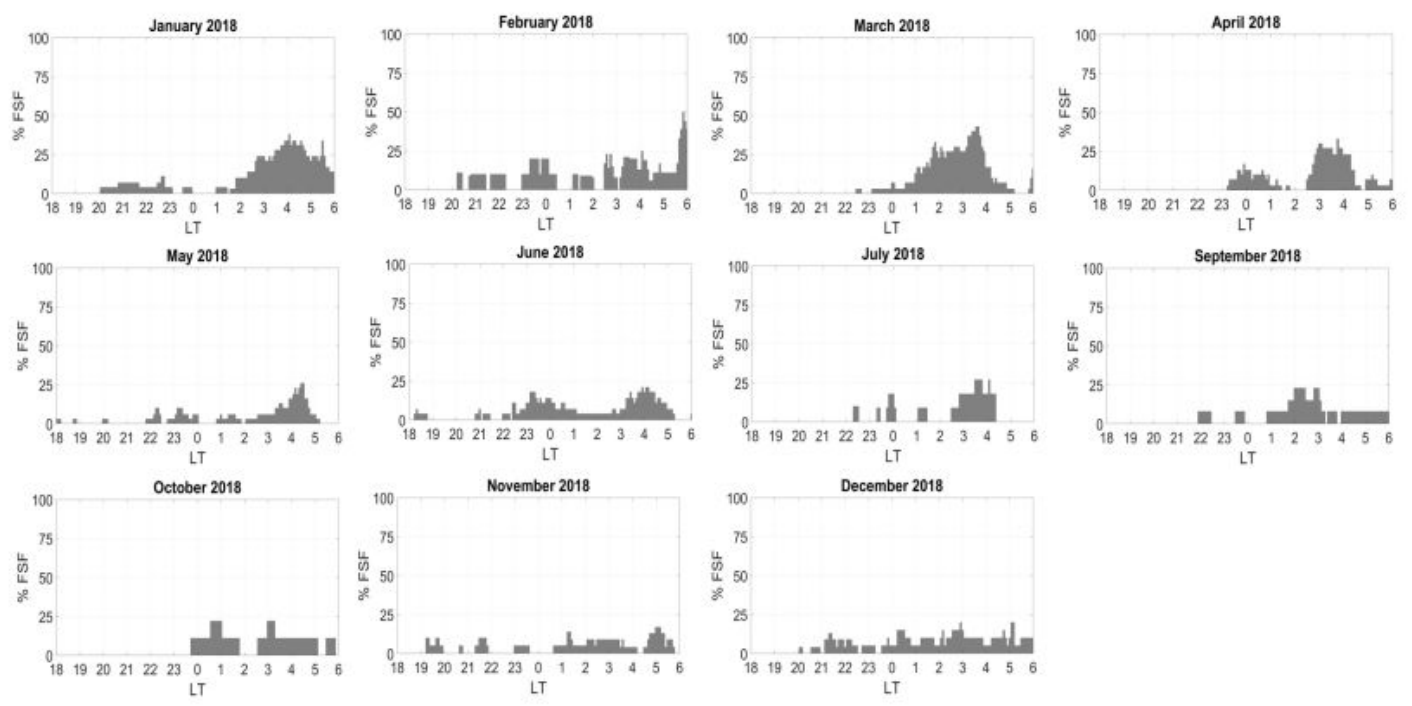

c) Strong range Spread-F (SSF)
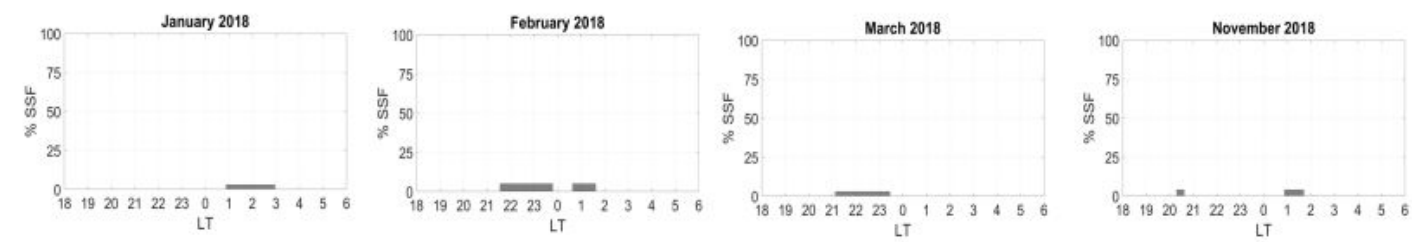

\section{Figure 7}

Monthly occurrence rate of a) range spread- $F(R S F), b)$ frequency spread- $F$ (FSF) and c) strong range spread-F (SSF) over Tucumán station during 2018. 
a) Range Spread-F (RSF)

\section{9}
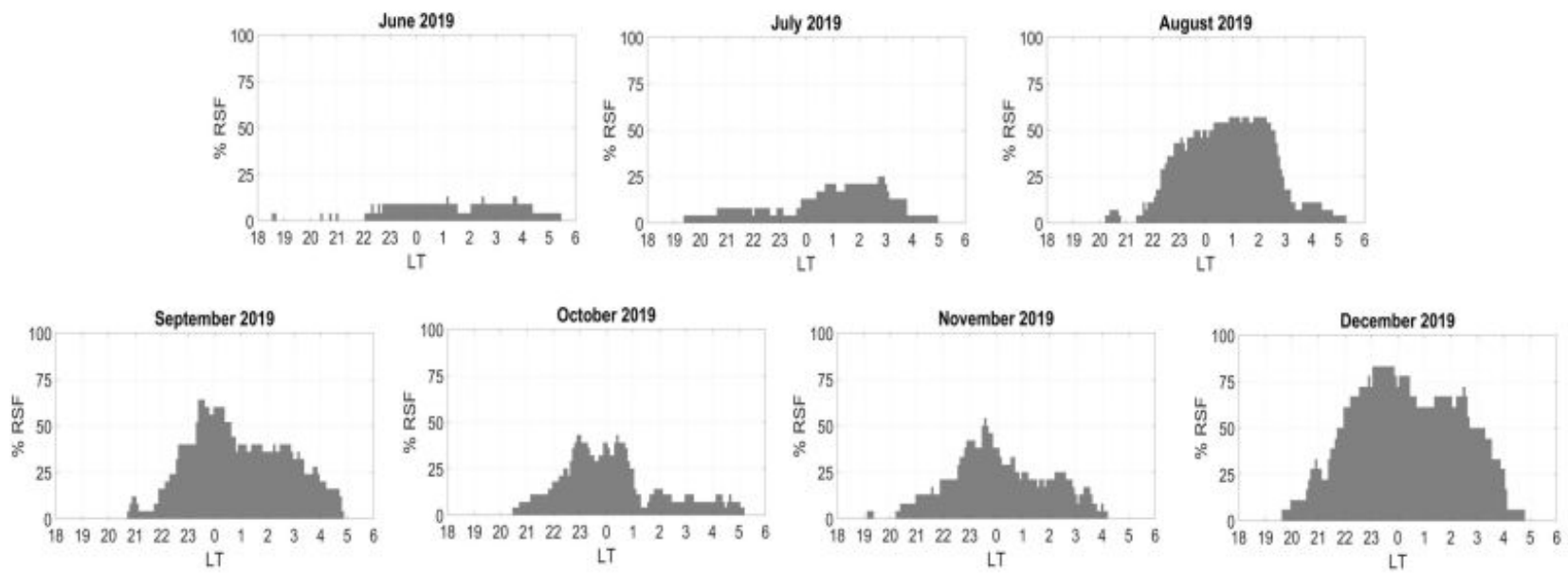

\section{b) Frequency Spread-F (FSF)}
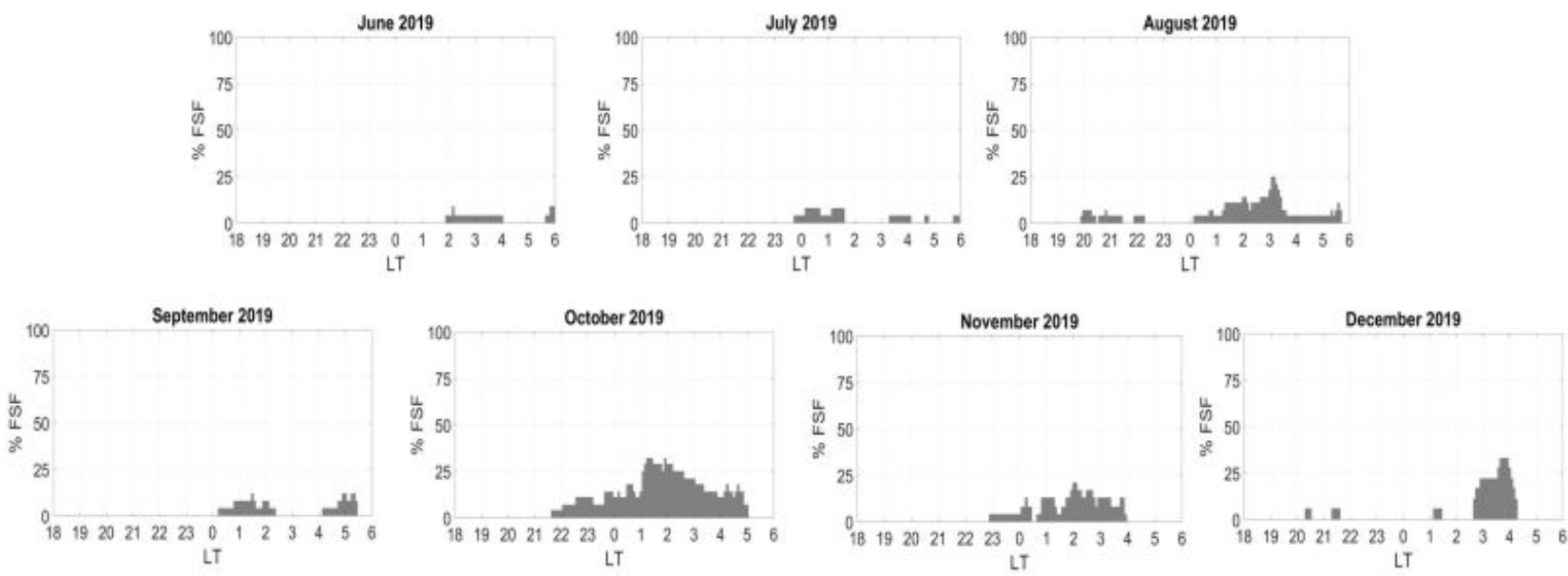

\section{c) Strong range Spread-F (SSF)}
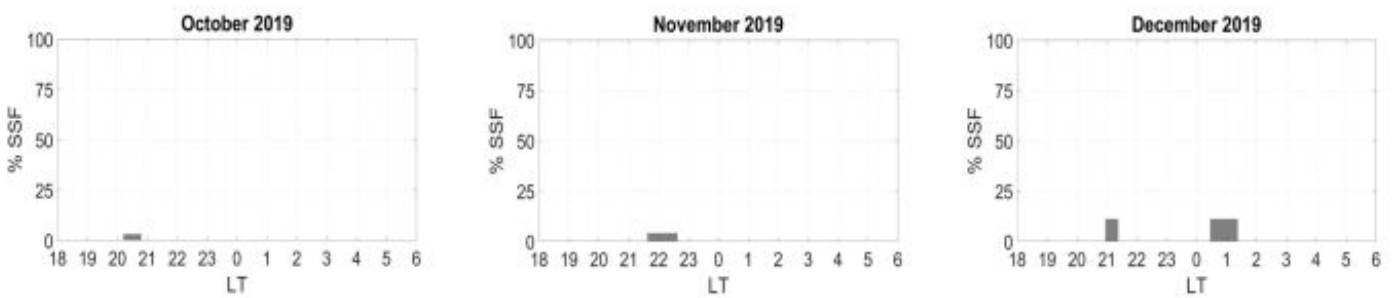

\section{Figure 8}

Monthly occurrence rate of a) range spread- $F(R S F), b)$ frequency spread- $F(F S F)$ and c) strong range spread-F (SSF) over Tucumán station during 2019. 
a

Nov 2014 - Dic 2015

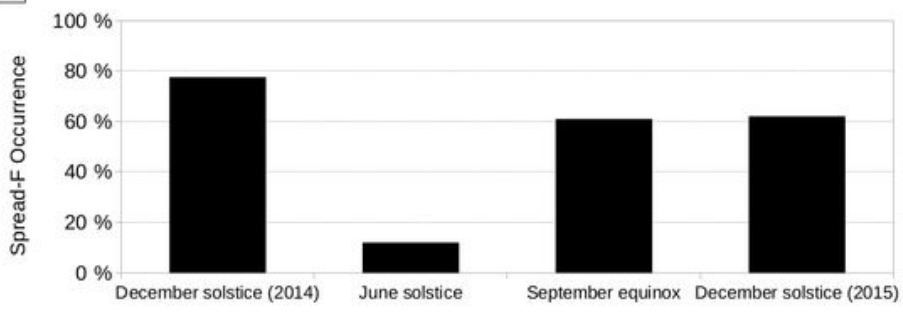

b

2016

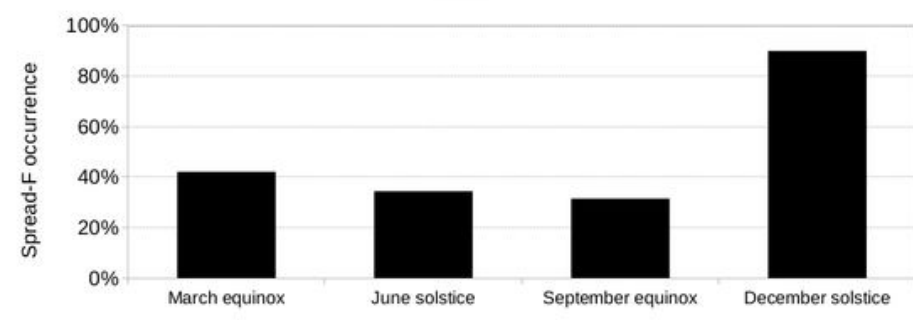

C

2017

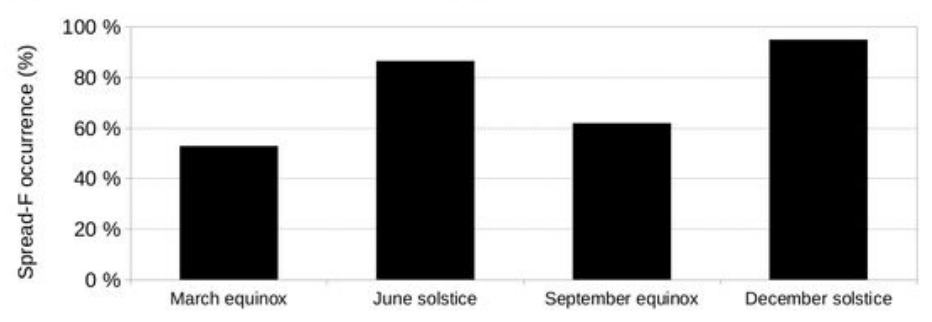

d

2018

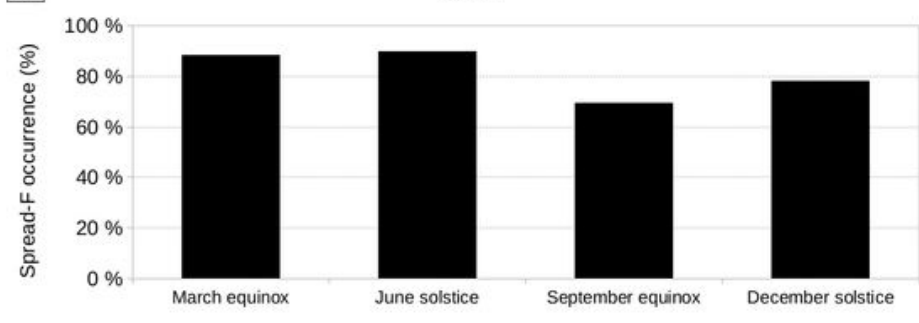

e

2019

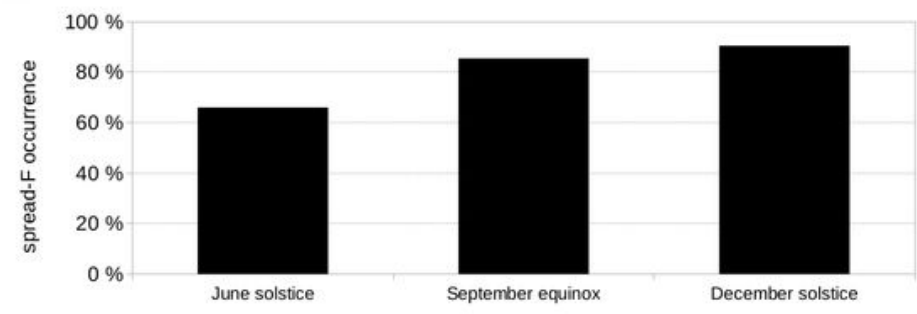

Figure 9

Seasonal occurrence rate of spread-F in Tucumán during November 2014-December 2019. This is the percentage of days with at least one spread $\mathrm{F}$ event daily in a season. 
Nov 2014 - Feb 2015
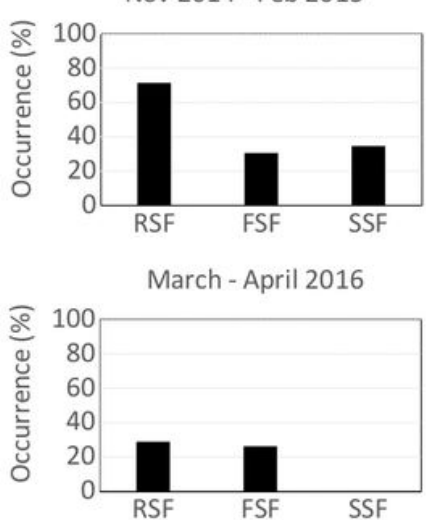

March - April 2017

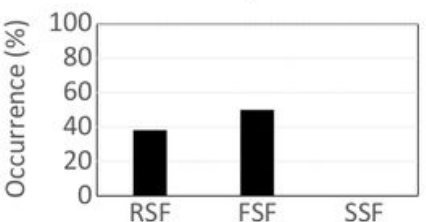

March - April 2018
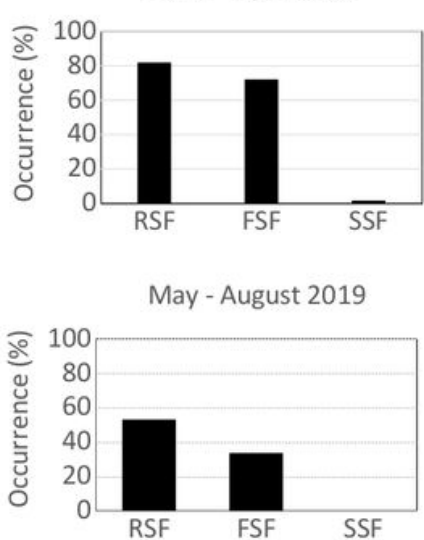

July - August 2015

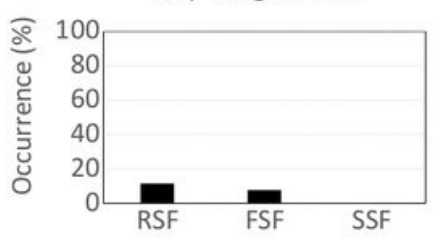

May - August 2016
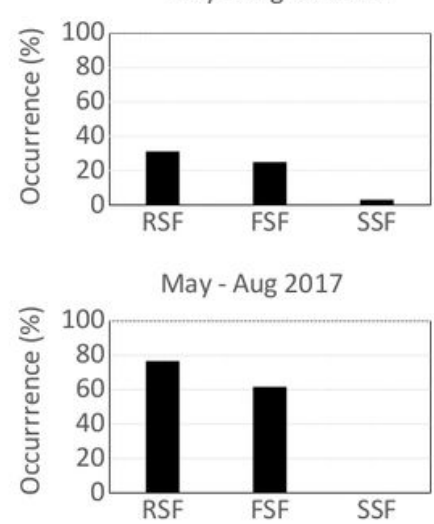

May - Aug 2018

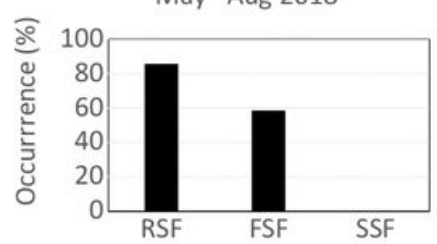

Sept - Oct 2019

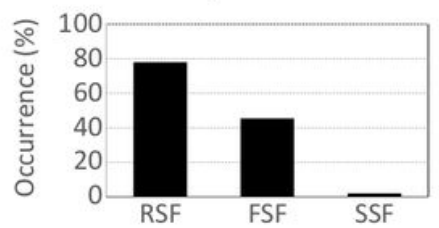

Sept - Oct 2015

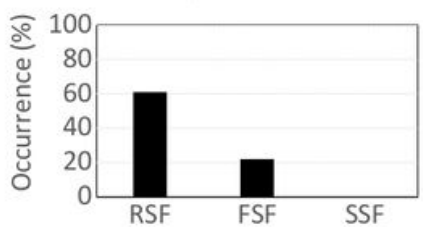

Sept - Oct 2016
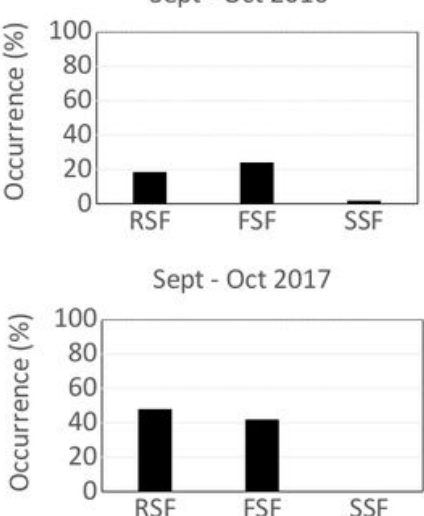

Sept - Oct 2018

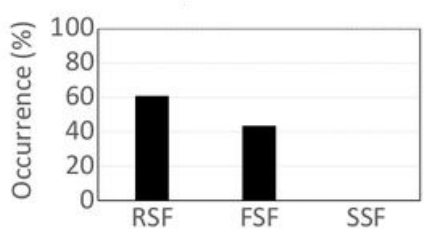

Nov - Dec 2019

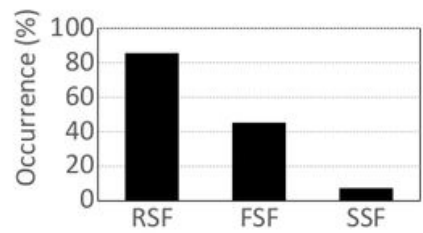

Nov 15 - Feb 16

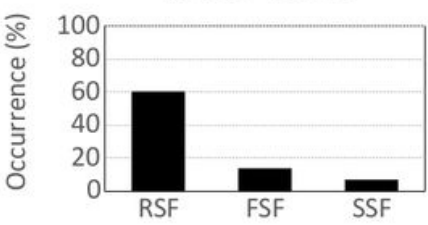

Nov 16 - Feb 17

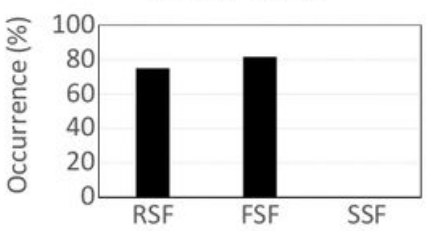

Nov 2017 - Feb 2018

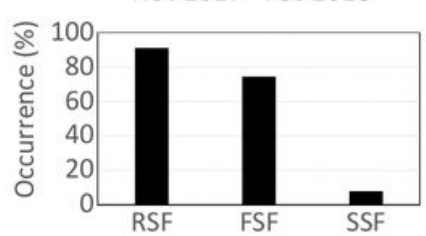

Nov - Dec 2018

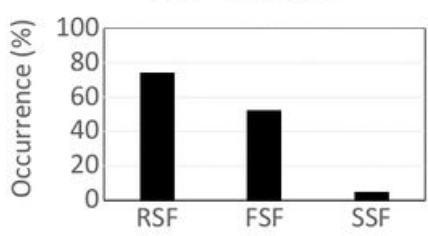

Figure 10

Seasonal occurrence rate of different types of spread-F (RSF, FSF and SSF) in Tucumán from November 2014 to December 2019. 


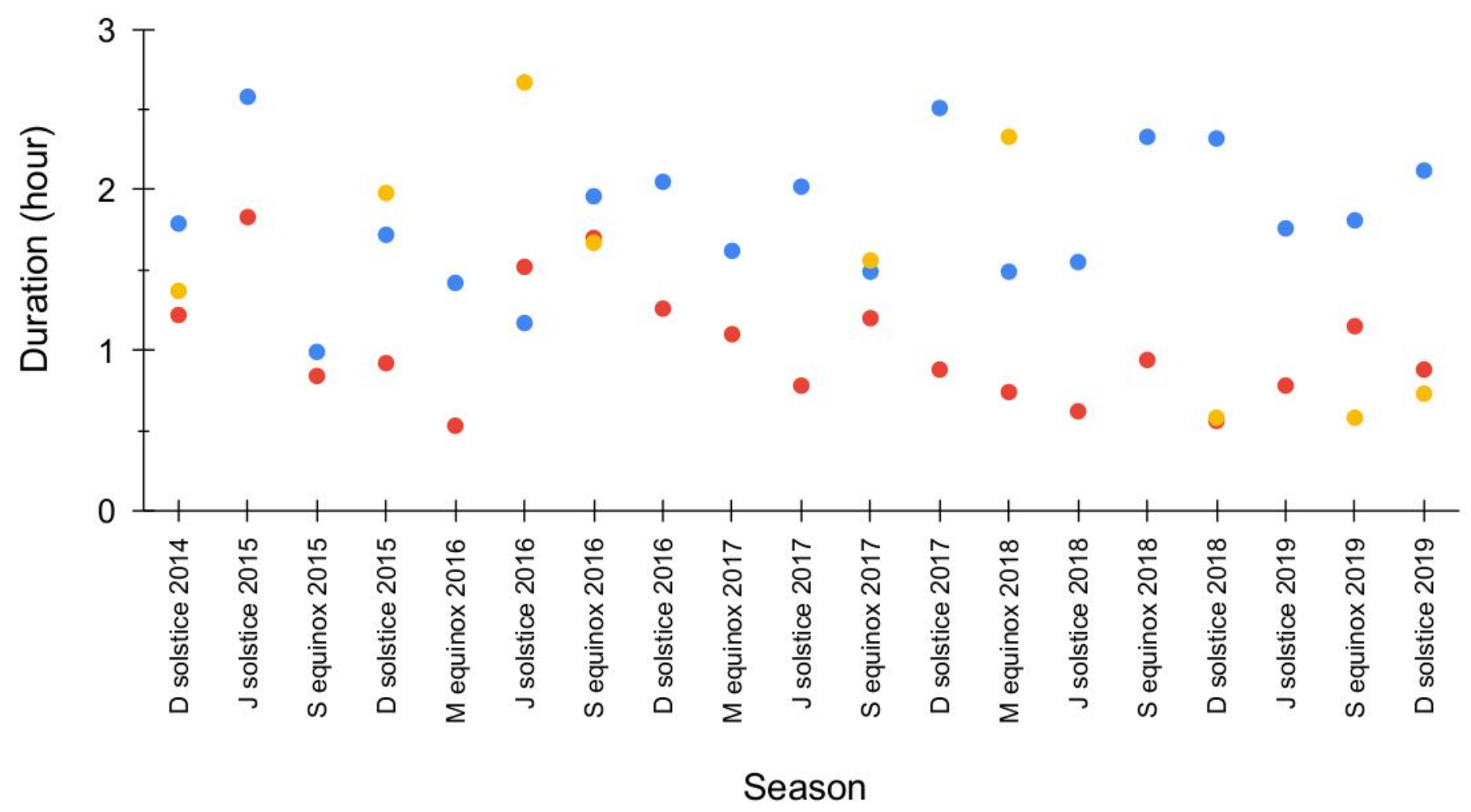

Figure 11

Seasonal variation of the mean RSF (blue), FSF (red) and SSF (yellow) duration in Tucumán from November 2014 to December 2019 (M: March, J: June, S: September, D: December). 

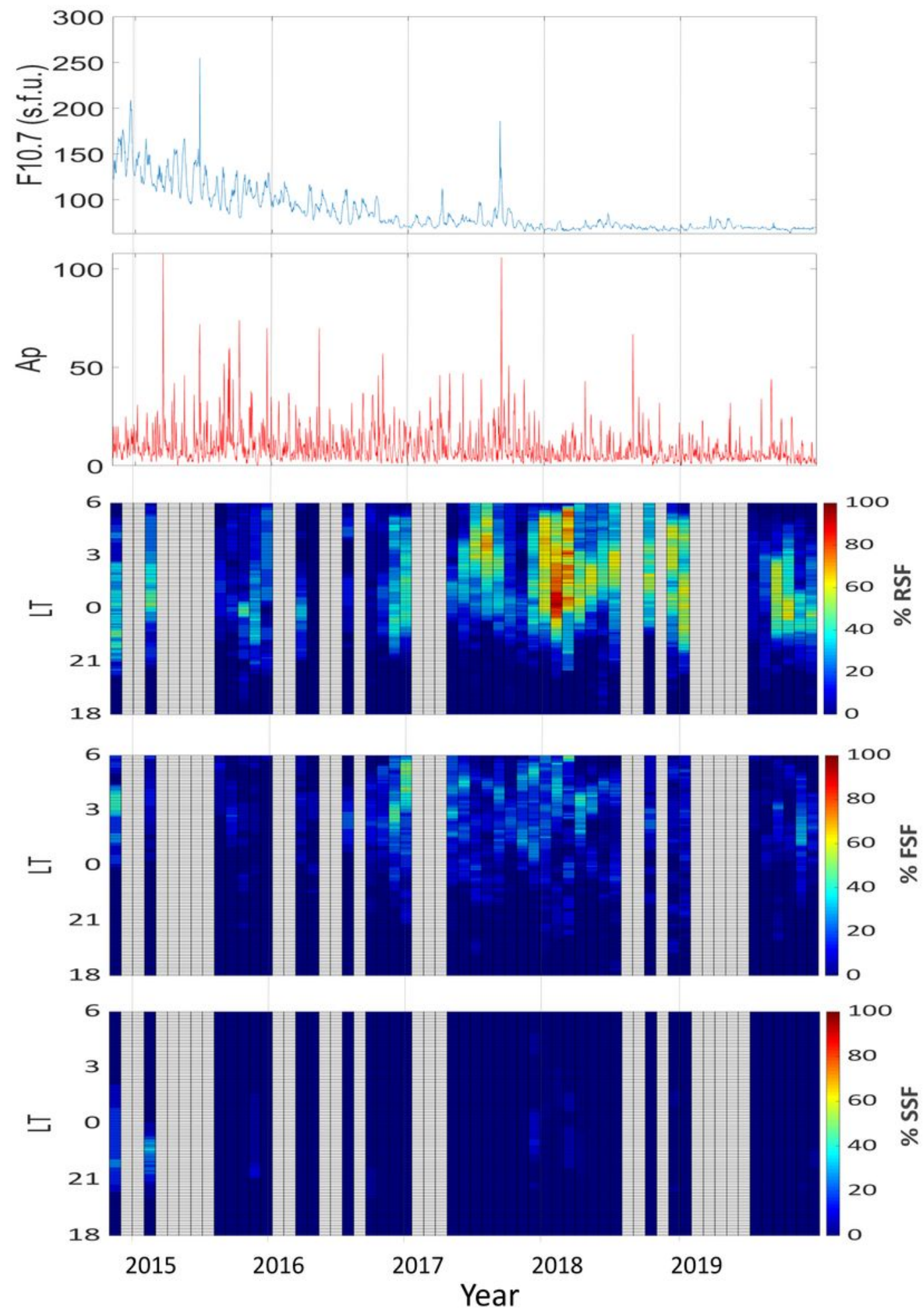

Figure 12

From top to bottom: daily F10.7, Ap index and monthly mean of RSF, FSF and SSF occurrence percentages in Tucumán from November 2014 to December 2019. Grey regions indicate data gaps. 

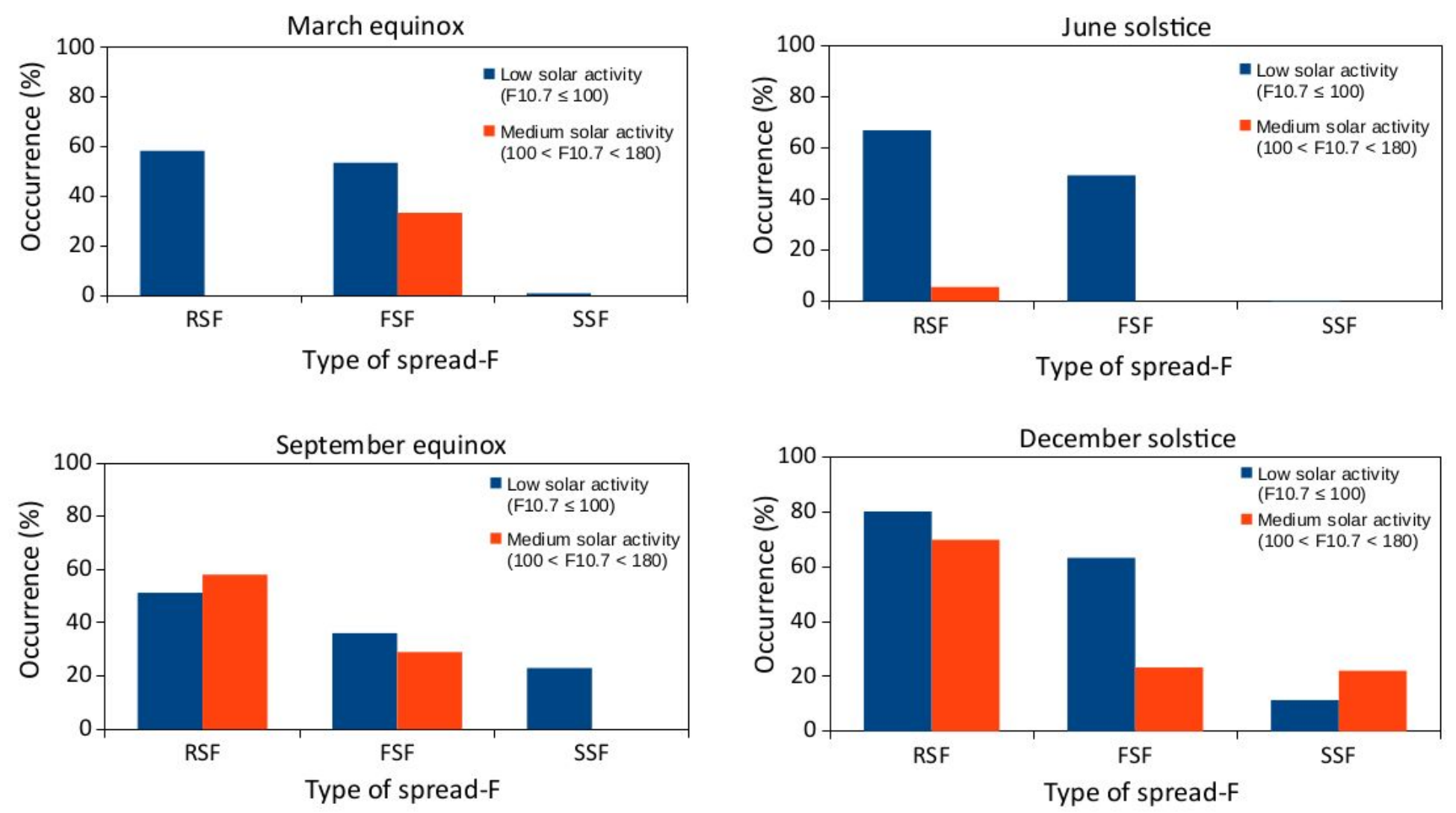

\section{Figure 13}

Occurrence rates of three types of spread-F under low (blue) and medium (orange) solar activity levels in Tucumán during November 2014 - December 2019.
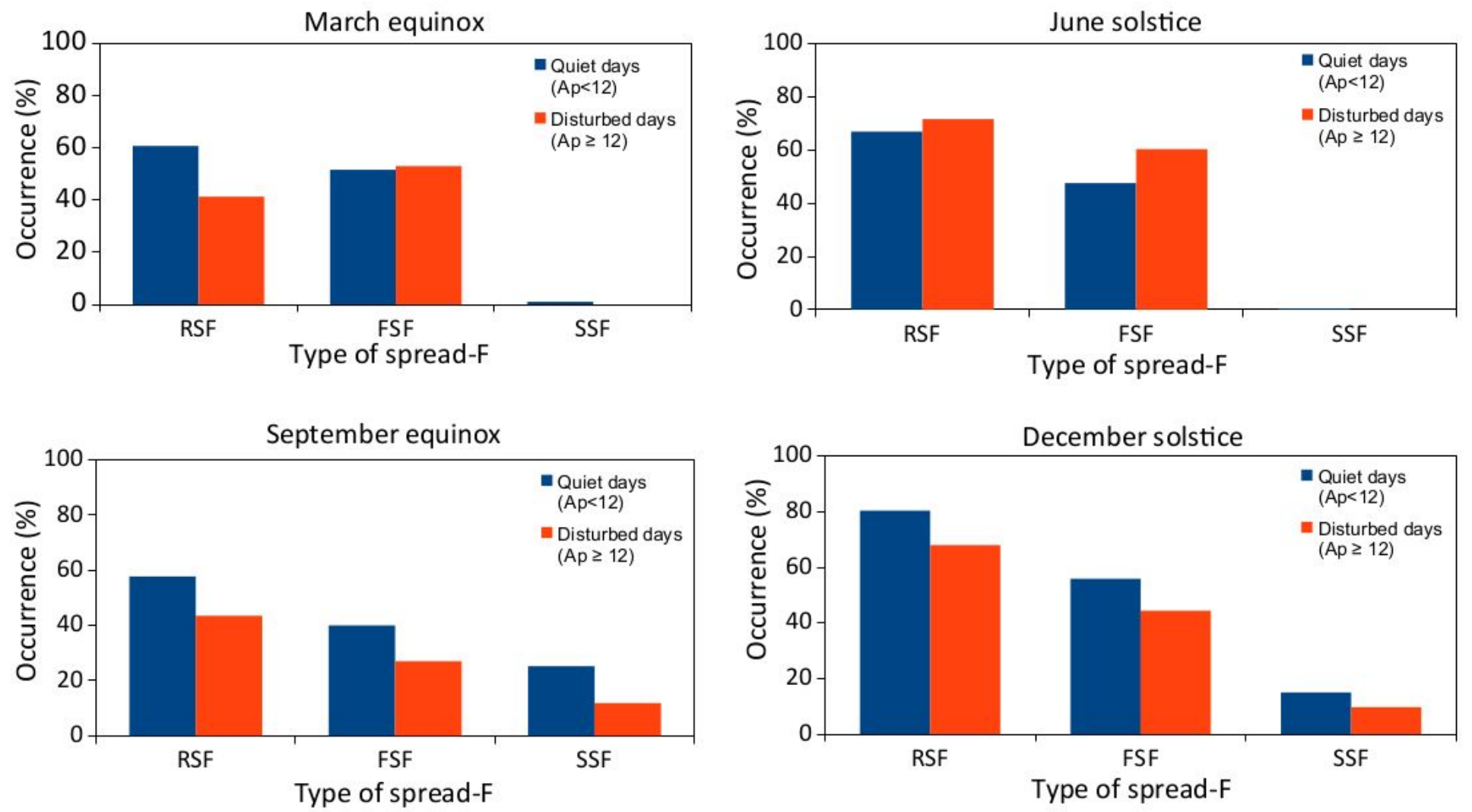
Figure 14

Occurrence rates of three types of spread-F under quiet (blue) and disturbed (orange) geomagnetic conditions in Tucumán during November 2014 - December 2019.
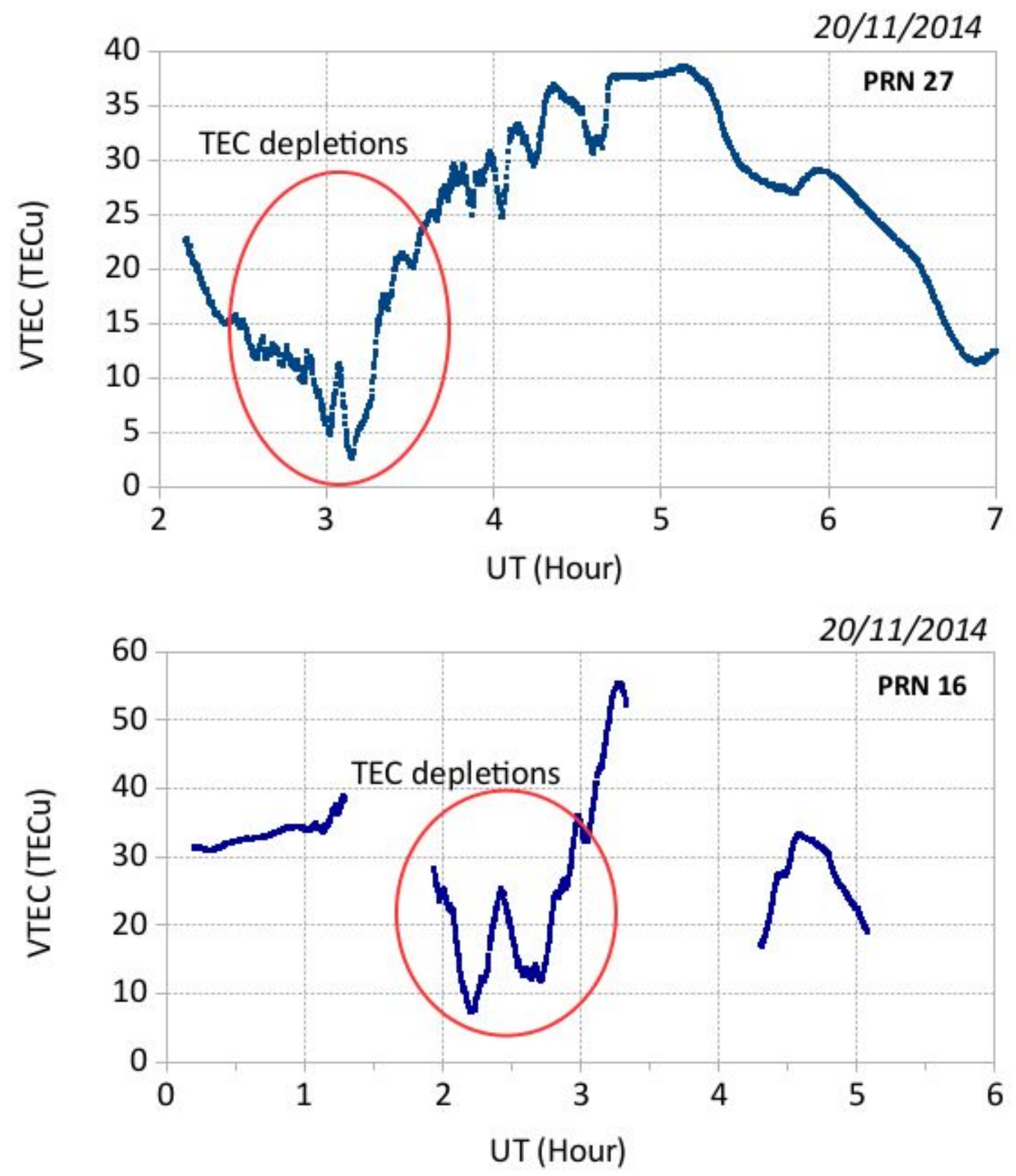

Figure 15

Plasma bubbles signatures (TEC depletion) in Tucumán during 20/11/14 for PRN 27 (top) and PRN 16 (bottom). 

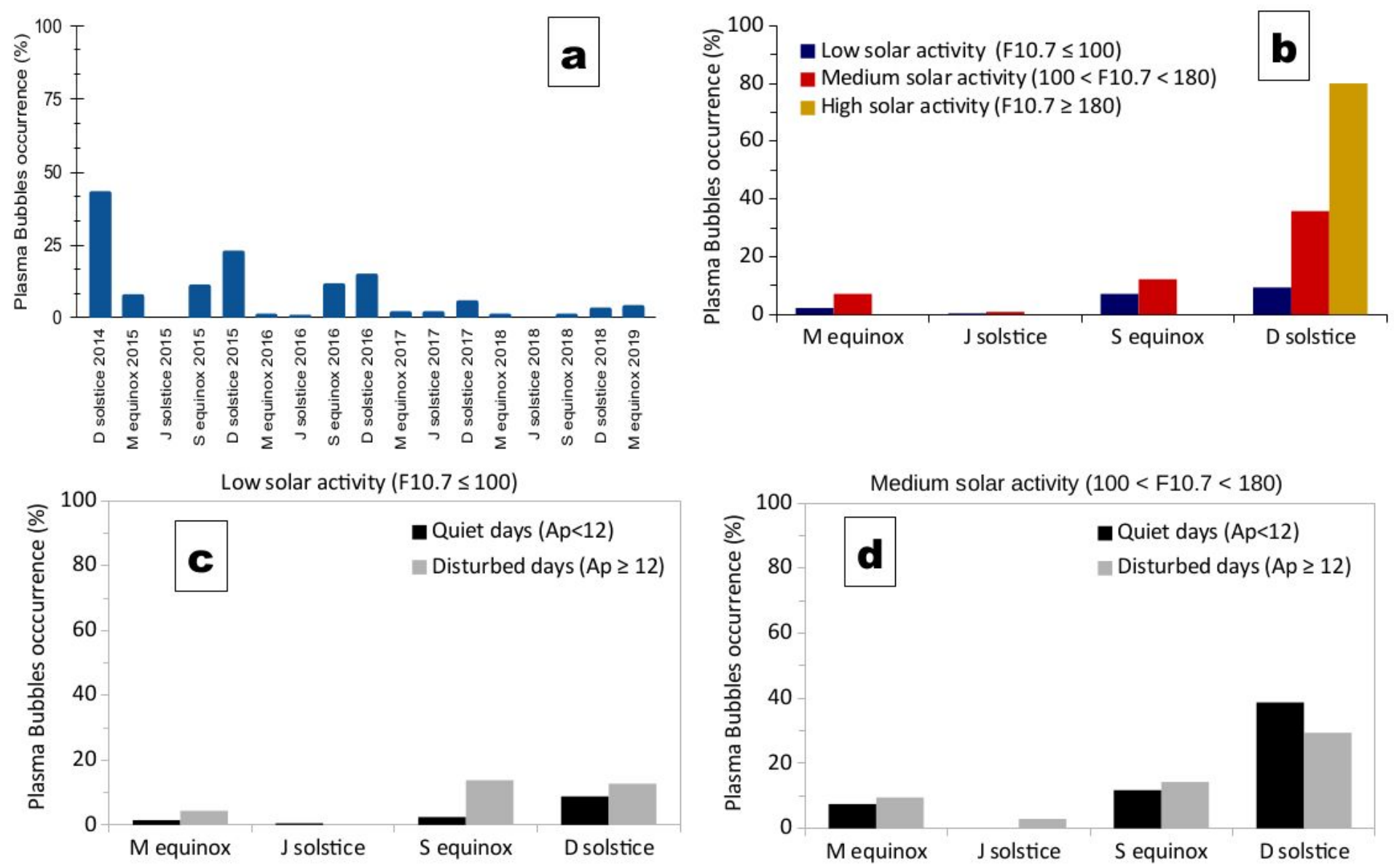

Figure 16

a) Seasonal variation of the occurrence of Plasma Bubbles over Tucumán for the period November 2014 - March 2019 (M: March, J: June, S: September, D: December). b) Plasma bubbles occurrence rate under low (dark blue), medium (orange) and high (yellow) solar activity levels. c) Plasma bubbles occurrence rate under quiet (black) and disturbed (grey) geomagnetic conditions under low solar activity. d) Same as c) but under medium solar activity. 